Energy Tochnology Division Energy Technology Division Energy Technology Division Energy Technology Division Energy Technology Division Energy Technology Division Energy Technology Division Energy Technology Division Energy Technolocy Division Energy Technology Division Energy Technology Division Energy Technology Division Energy Technology Division Energy Technology Division Energy Tochnology Dwision Energy Technology Divislon Energy Technolocy Division Energy Technoloty Division Energy Technology Dhision Energy Technology Division Energy Technology Division Energy Technology Division Energy Technology Division Energy Technology Division Energy Technology Division Energy Technology Division Energy Technology Division Energy Technology Division

\section{Estimation of Maximum Temperature in a Package Subjected to Hypothetical-Accident Thermal-Test Conditions}

\author{
by V. L. Shah
}

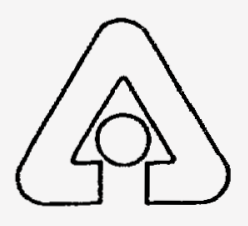

Argonne National Laboratory, Argonne, Illinois 60439

operated by The University of Chicago

for the United States Department of Energy under Contract W-31-109-Eng-38

\footnotetext{
Enorgy Tochnology Division

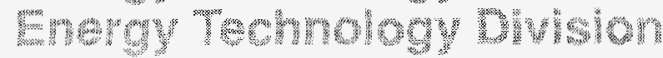
Eneroy Tromnlogy DWhlow Emergy "Wohnology Division

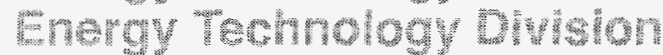
meryy Temmoloy Mivish mergy Townolony DMusim Enorgy Tormology musion
} 
Argonne National Laboratory, with facilities in the states of Illinois and Idaho, is owned by the United States government, and operated by The University of Chicago under the provisions of a contract with the Department of Energy.

\section{DISCLAIMER}

This report was prepared as an account of work sponsored by an agency of the United States Government. Neither the United States Government nor any agency thereof, nor any of their employees, makes any warranty, express or implied, or assumes any legal liability or responsibility for the accuracy, completeness, or usefulness of any information, apparatus, product, or process disclosed, or represents that its use would not infringe privately owned rights. Reference herein to any specific commercial product, process, or service by trade name, trademark, manufacturer, or otherwise, does not necessarily constitute or imply its endorsement, recommendation, or favoring by the United States Government or any agency thereof. The views and opinions of authors expressed herein do not necessarily state or reflect those of the United States Government or any agency thereof.

Reproduced from the best available copy.

Available to DOE and DOE contractors from the Office of Scientific and Technical Information

$$
\text { P.O. Box } 62
$$

Oak Ridge, TN 37831

Prices available from (423) 576-8401

Available to the public from the National Technical Information Service

U.S. Department of Commerce 5285 Port Royal Road Springfield, VA 22161 
Distribution

Category:

Nuclear Safety

UC-2020

ARGONNE NATIONAL LABORATORY

9700 South Cass Avenue, Argonne, IL 60439

ANL-96/12

\title{
ESTIMATION OF MAXIMUM TEMPERATURE IN A PACKAGE SUBJECTED TO HYPOTHETICAL-ACCIDENT THERMAL-TEST CONDITIONS
}

\author{
by \\ V. L. Shah \\ Energy Technology Division \\ Transportation of Hazardous Materials Section
}

May 1996

Work Sponsored by

U.S. DEPARTMENT OF ENERGY

Office of Facility Safety Analysis, under Contract W-31-109-Eng-38 



\section{DISCLAMMER}

Portions of this document may be illegible in electronic image products. Images are produced from the best available original document. 


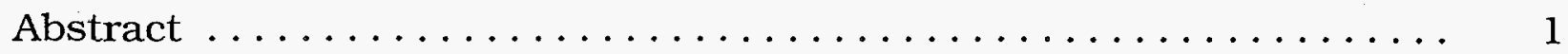

1 Introduction $\ldots \ldots \ldots \ldots \ldots \ldots \ldots \ldots \ldots \ldots \ldots \ldots \ldots \ldots \ldots \ldots \ldots$

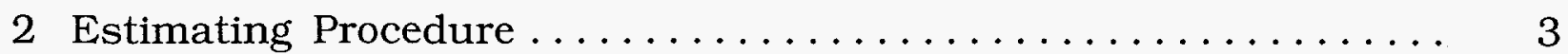

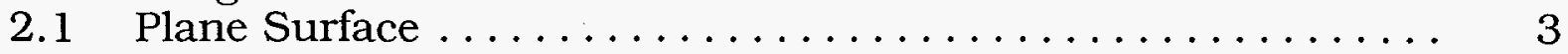

2.2 Cylindrical Surface $\ldots \ldots \ldots \ldots \ldots \ldots \ldots \ldots \ldots \ldots \ldots \ldots$

3 Temperature in a Semi-Infinite Solid $\ldots \ldots \ldots \ldots \ldots \ldots \ldots \ldots$

3.1 Governing Equation $\ldots \ldots \ldots \ldots \ldots \ldots \ldots \ldots \ldots \ldots \ldots \ldots \ldots$

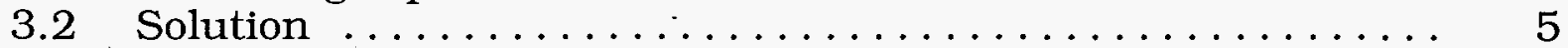

3.3 Hypothetical-Accident Conditions .............. 6

3.4 Maximum Temperature $\ldots \ldots \ldots \ldots \ldots \ldots \ldots \ldots . \ldots .6$

4 Temperature in an Infinite Circular Cylinder $(Q=0) \ldots \ldots \ldots \ldots$

4.1 Governing Equation $\ldots \ldots \ldots \ldots \ldots \ldots \ldots \ldots \ldots \ldots \ldots \ldots$

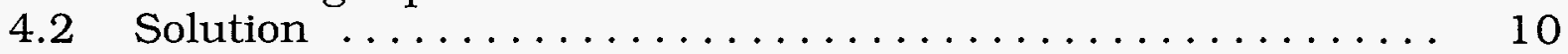

4.3 Hypothetical-Accident Conditions ............... 11

4.4 Maximum Temperature $\ldots \ldots \ldots \ldots \ldots \ldots \ldots \ldots \ldots \ldots . \ldots \ldots$

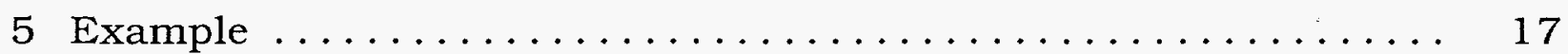

5.1 Mound 9859 Tritium Trap Package .............. 17

5.2 Temperature Estimation $\ldots \ldots \ldots \ldots \ldots \ldots \ldots \ldots \ldots \ldots \ldots \ldots$

5.3 Numerical Solution ..................... 20

5.4 Comparison of Predicted and Estimated

Maximum Temperatures .................. 20

6 Temperature in an Infinite Circular Cylinder $(\mathrm{Q} \neq 0) \ldots \ldots \ldots 20$

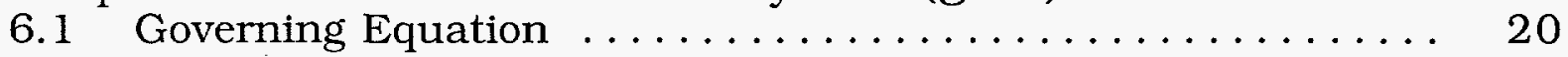

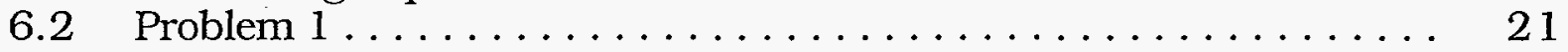

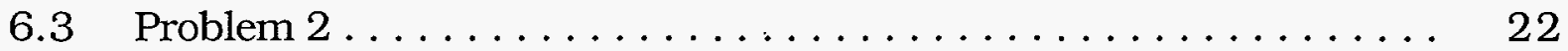

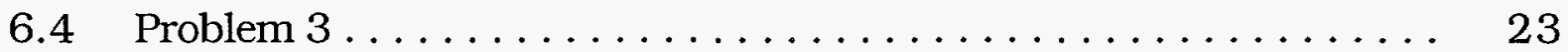

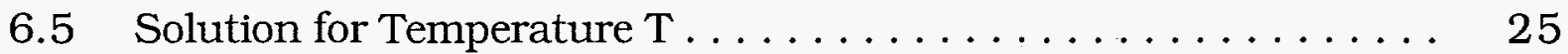

6.6 Effect of Heat Source .................... 26

6.7 Hypothetical-Accident Conditions $\ldots \ldots \ldots \ldots \ldots \ldots \ldots 26$

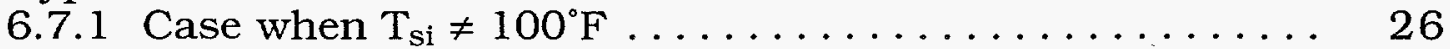

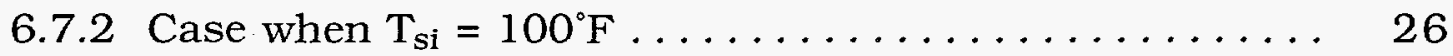

6.8 Maximum Temperature $\ldots \ldots \ldots \ldots \ldots \ldots \ldots \ldots \ldots \ldots \ldots \ldots \ldots \ldots$

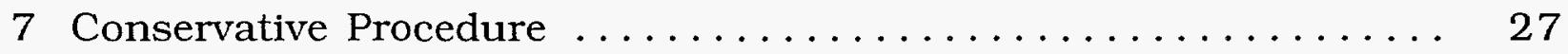

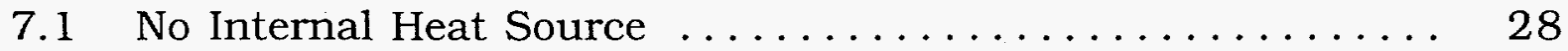

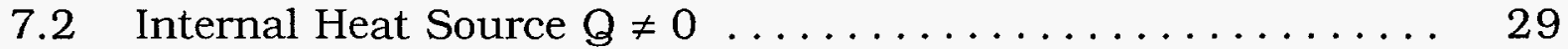

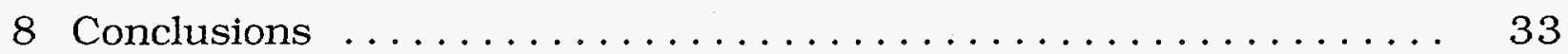

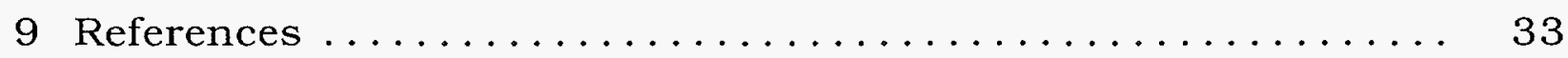




\section{FIGURES}

1. Package with plane and cylindrical surface overpacks $\ldots . \ldots \ldots 3$

2. Graphical representation of step surface temperature

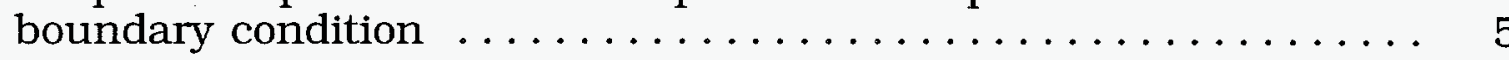

3. Step surface temperature condition to represent a hypothetical-accident thermal test ................ 6

4. Temperature at time $=30 \mathrm{~min}$ in a semi-infinite solid subjected to $1475^{\circ} \mathrm{F}$ step temperature change at the surface $\ldots .66$

5. Maximum temperature and time to attain maximum temperature in a semi-infinite solid subjected to $1475^{\circ} \mathrm{F}$ step temperature change at the surface ..............

6. Temperature at time $=30 \mathrm{~min}$ in an infinite cylinder subjected to $1475^{\circ} \mathrm{F}$ step temperature change at the surface $\ldots . .12$

7. Maximum temperature in an infinite cylinder subjected to $1475^{\circ} \mathrm{F}$ step temperature change at the surface $\ldots \ldots \ldots \ldots \ldots 14$

8. Time to attain maximum temperature in an infinite cylinder subjected to $1475^{\circ} \mathrm{F}$ step temperature change at the surface $\ldots \ldots 14$

9. Actual and computer model of Mound 9859 tritium trap

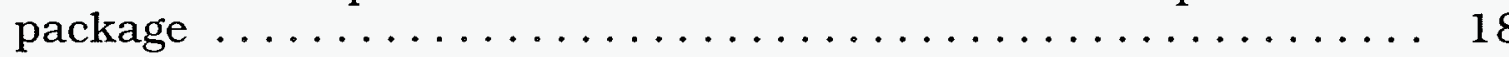

10. Maximum temperature at Location A in the Mound 9859 tritium trap package, estimated from Fig. $5 \ldots \ldots \ldots \ldots 18$

11. Maximum temperature at Location B in the Mound 9859 tritium trap package, estimated from Fig. $7 \ldots \ldots \ldots \ldots \ldots$

12. Surface temperature conditions experienced by package under hypothetical-accident thermal test specified in 10 CFR $\$ 71.73$ and imposed in the analytical model ......... 28

13. Steady-state temperature distributions in two solids, one with uniform diffusivity, the other with two diffusivities ...... 30

14. Asymptotic temperature distribution in two packages, one with, the other without an internal heat source, as ambient temperature is raised from $T_{0}$ to $T_{\mathrm{S} 1}$ and held at $\mathrm{T}_{\mathrm{s} 1}$ for infinite time $\ldots \ldots \ldots \ldots \ldots \ldots \ldots \ldots \ldots \ldots \ldots$ 


\section{TABLES}

1. Temperature in a semi-infinite solid at time $=30 \mathrm{~min}$ for various values of $x^{2} / \alpha \ldots \ldots \ldots \ldots \ldots \ldots \ldots \ldots \ldots \ldots \ldots$

2. Maximum temperature and time to attain maximum temperature for various values of $\mathrm{x}^{2} / \alpha \ldots \ldots \ldots \ldots \ldots \ldots$

3. Temperature in an infinite cylinder at time $=30 \mathrm{~min}$ for various values of $\mathrm{R}^{2} / \alpha$ and $\mathrm{r}^{*}(=\mathrm{r} / \mathrm{R}) \ldots \ldots \ldots \ldots \ldots$

4. Maximum temperature in an infinite cylinder for various values of $R^{2} / \alpha$ and $r^{*}(=r / R) \ldots \ldots \ldots \ldots \ldots$

5. Time (min) to attain maximum temperature in an infinite cylinder for various values of $R^{2} / \alpha$ and $r^{*}(=r / R) \ldots \ldots \ldots 16$

6. Maximum temperature at Locations A and B in Fig. 9b . . . . . . 19 


\title{
ESTIMATION OF MAXIMUM TEMPERATURE IN A PACKAGE SUBJECTED TO HYPOTHETICAL-ACCIDENT THERMAL-TEST CONDITIONS
}

by

\author{
V. L. Shah
}

\begin{abstract}
A simple reading-the-graph procedure has been developed to provide a quick estimate of maximum temperature in a package during hypotheticalaccident thermal-test conditions. The procedure, based on applying the analytical solutions of a transient thermal-diffusion equation for temperatures in a semi-infinite solid and in an infinitely long circular cylinder subjected to step surface temperature boundary conditions, is applicable to all packages, with or without an internal heat source, that are protected by rectangular or cylindrical thermal insulating overpacks. Simple to follow, the procedure provides a conservative estimate of package maximum temperatures during hypothetical-accident thermal-test conditions. To demonstrate its applicability, the procedure is applied to the Mound 9859 tritium trap package and two values of the thermal diffusivity of the insulation in the overpack.
\end{abstract}

\section{INTRODUCTION}

To ensure that a package for the transportation of radioactive materials is designed adequately to meet the requirements specified in the Code of Federal Regulations, Title 10, Part 71 (10 CFR \$71), we must know the maximum temperatures that the package may attain during normal transport and under hypothetical-accident thermal-test conditions. The test conditions for a hypothetical-accident thermal event, specified in 10 CFR \$71.73, are

- Expose the whole package to a radiation environment at $800^{\circ} \mathrm{C}$ $\left(1475^{\circ} \mathrm{F}\right)$ for $30 \mathrm{~min}$, and

- Maintain the ambient temperature at $38^{\circ} \mathrm{C}\left(100^{\circ} \mathrm{F}\right)$ before and after the 30-min test. 
To determine package temperature during a hypothetical-accident thermal event, designers and reviewers generally perform detailed analyses with computer codes. These detailed analyses and the required solution of thermal-diffusion equations are time-consuming and labor-intensive. Some simple conservative estimating procedures are therefore preferred because the very detailed and time-consuming numerical computation can be avoided if the results of the simple conservative estimation can show that a package meets the requirements of the Federal Code.

In this report, a simple procedure is presented that provides a quick and conservative estimation of package maximum temperatures $T_{\max }(x)$ at a distance $x$ from the surface of the package under hypothetical-accident thermal-test conditions. The procedure, which is applicable to all packages, with or without an internal heat source, that are protected by rectangular or cylindrical thermal insulating overpacks, can be used to estimate package maximum temperatures before commencing a very lengthy and timeconsuming computer analysis. In addition, the method can be used to check the results of a detailed numerical solution to ensure that no major modeling or input errors have been made in the analysis performed with a computer code.

The estimating procedure, described in Section 2, is based on applying the analytical solutions for temperature in a semi-infinite solid and in an infinitely long circular cylinder subjected to step surface temperature boundary conditions. These analytical solutions are presented in Sections 3 and 4 , respectively.

To demonstrate the applicability of the procedure, the Mound 9859 tritium trap package and two values of thermal diffusivity of the insulation in the overpack are presented as examples in Section 5. The maximum temperatures estimated by the procedure are compared with those obtained by numerical simulations of a very detailed computer model of the package.

The analytical solution for temperature in an infinitely long, internalheat-source-containing circular cylinder that has been subjected to step surface temperature boundary conditions is described in Section 6 . In Section 7 , the results of this analysis and other qualitative examples are used to show that the proposed method will provide a conservative estimate. Concluding remarks are presented in Section 8. 


\section{ESTIMATING PROCEDURE}

The estimating procedure presented here is applicable to all packages with plane or cylindrical surface overpacks, as shown in Figs. 1(a) and 1(b), respectively.

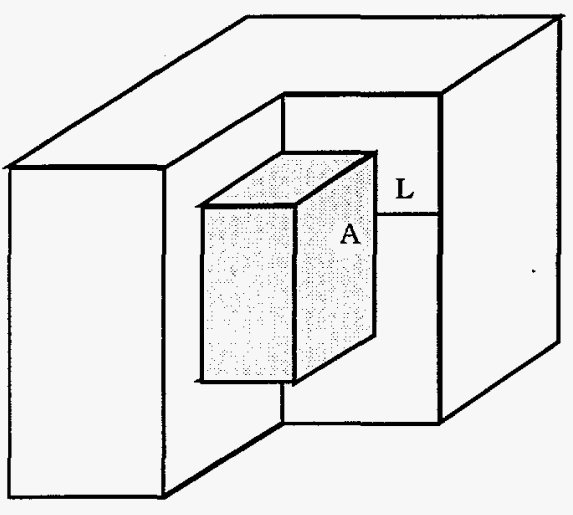

(a)

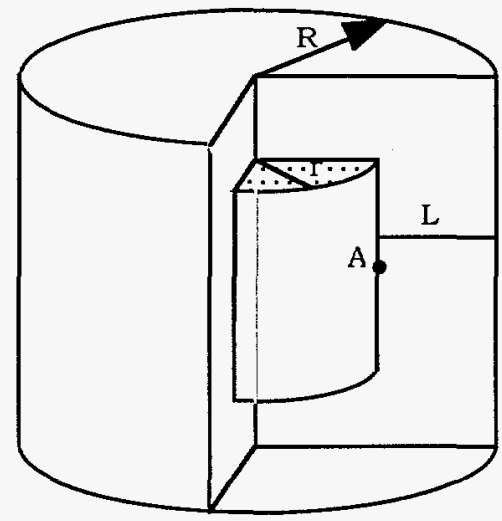

(b)

Fig. 1. Package with (a) plane and (b) cylindrical surface overpacks

\subsection{PLANE SURFACE}

The procedure for estimating maximum temperature at location $\mathrm{A}$ in Fig. 1a at distance $\mathrm{L}$ from a plane surface of the overpack is

- Calculate the parameter $\mathrm{L}^{2} / \alpha$ (s), where $\mathrm{L}$ (in.) is the distance from the surface of the overpack and $\alpha$ (in. ${ }^{2} / \mathrm{s}$ ) is the thermal diffusivity of the overpack insulation.

- Read the maximum temperature $T_{A, m a x}$-analytic, $q=0$ from a plot of the maximum temperature vs. the distance from the surface squared/thermal diffusivity (presented in Section 3.4).

- Calculate the rise in temperature

$$
\mathrm{dT}_{\mathrm{A}, \mathrm{q}-\text { steady }}=\mathrm{T}_{\mathrm{A}, \mathrm{t}=0}-100
$$

from the initial steady-state temperature distribution $T_{x, t=0}$.

- Estimate the maximum temperature from

$$
\mathrm{T}_{\mathrm{A}, \text { max-estimation }}=\mathrm{T}_{\mathrm{A}, \max \text {-analytic }, \mathrm{q}=0}+\mathrm{d} \mathrm{T}_{\mathrm{A}, \mathrm{q} \text {-steady }} \text {. }
$$




\subsection{CYLINDRICAL SURFACE}

The procedure for estimating maximum temperature at location $\mathrm{A}$, at a radial distance $L$ from a cylindrical surface, in Fig. $1 \mathrm{~b}$ is

- Calculate the parameters $\mathrm{r}^{*}(=\mathrm{r} / \mathrm{R}=1-[\mathrm{L} / \mathrm{R}])$ and $\mathrm{R}^{2} / \alpha(\mathrm{s})$, where $\mathrm{L}$ (in.) is the radial distance from the outer surface, $R$ (in.) is the outer radius and $\alpha\left(\mathrm{in}^{2} / \mathrm{s}\right)$ is the thermal diffusivity of the overpack insulation.

- Read the maximum temperature $T_{A, \max }$-analytic, $q=0$, from a plot of the maximum temperature vs. the outer radius squared/thermal diffusivity (presented in Section 4.4).

- Calculate the rise in temperature

$$
\mathrm{dT}_{\mathrm{A}, \mathrm{q} \text {-steady }}=\mathrm{T}_{\mathrm{A}, \mathrm{t}=0}-100
$$

from the initial steady-state temperature distribution $T_{r, t=0}$.

- Estimate the maximum temperature from

$$
\mathrm{T}_{\mathrm{A}, \text { max-estimation }}=\mathrm{T}_{\mathrm{A}, \text { max-analytic, } \mathrm{q}=0}+\mathrm{dT}_{\mathrm{A}, \mathrm{q} \text {-steady }} \text {. }
$$

\section{TEMPERATURE IN A SEMI-INFINITE SOLID}

The analysis for temperature in a semi-infinite solid, without an internal heat source but with step changes in the surface temperature, is presented here.

\subsection{GOVERNING EQUATION}

The governing equation for temperature in a semi-infinite solid without an internal heat source is

$$
\frac{\partial^{2} \mathrm{~T}}{\partial \mathrm{x}^{2}}-\frac{1}{\alpha} \frac{\partial \mathrm{T}}{\partial \mathrm{t}}=0
$$

where, $\mathrm{T}, \mathrm{x}, \alpha$, and $\mathrm{t}$ are the temperature, distance from the surface, thermal diffusivity, and time, respectively. 


\subsection{SOLUTION}

The one-dimensional analytical solution of Eq. 1 for a semi-infinite solid, initially at temperature $T_{0}$ and subjected to step surface temperatures $\mathrm{T}_{\mathrm{s} 1}$ for a time $<\mathrm{t}_{1}$, and $\mathrm{T}_{\mathrm{s} 2}$ for a time $>t_{1}$, i.e., is shown in Fig. 2 and given by Eq. 3 in Section 2.5 of Carslaw and Jaeger, ${ }^{2}$ is

$$
\frac{\left(T-T_{0}\right)}{\left(T_{s 1}-T_{0}\right)}=\operatorname{erfc}\left(\frac{\sqrt{x^{2} / \alpha}}{2 \sqrt{t}}\right)
$$

for $\mathrm{t} \leq \mathrm{t}_{1}$ and

$$
\frac{\left(T-T_{0}\right)}{\left(T_{s 1}-T_{0}\right)}=\operatorname{erfc}\left(\frac{\sqrt{x^{2} / \alpha}}{2 \sqrt{t}}\right)+\frac{\left(T_{s 2}-T_{s 1}\right)}{\left(T_{s 1}-T_{0}\right)} \operatorname{erfc}\left(\frac{\sqrt{x^{2} / \alpha}}{2 \sqrt{t-t_{1}}}\right)
$$

for $t>t_{1}$. Here, $\operatorname{erfc}(x)$ is the complimentary error function, defined as

$$
\operatorname{erfc}(x)=\frac{2}{\sqrt{\pi}} \int_{x}^{\infty} e^{-t^{2}} d t
$$

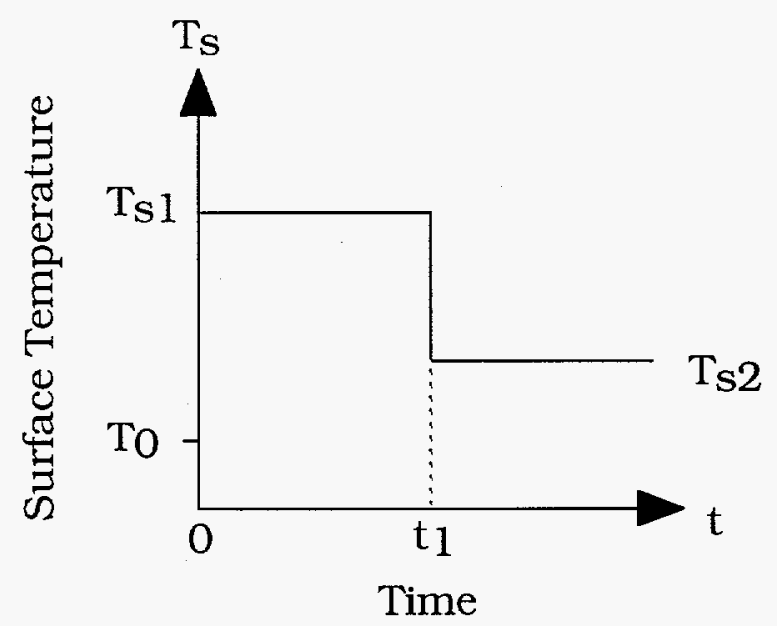

Fig. 2. Graphical representation of step surface temperature boundary condition 


\subsection{HYPOTHETICAL-ACCIDENT CONDITIONS}

The solutions of Eqs. 2 and 3 for the hypothetical-accident surface temperature boundary conditions shown in Fig. 3 are

$$
\frac{(T-100)}{(1375)}=\operatorname{erfc}\left(\frac{\sqrt{x^{2} / \alpha}}{2 \sqrt{t}}\right)
$$

for $\mathrm{t} \leq 1800 \mathrm{~s}(30 \mathrm{~min})$ and

$$
\frac{(T-100)}{(1375)}=\operatorname{erfc}\left(\frac{\sqrt{x^{2} / \alpha}}{2 \sqrt{t}}\right)-\operatorname{erfc}\left(\frac{\sqrt{x^{2} / \alpha}}{2 \sqrt{t-1800}}\right)
$$

for $\mathrm{t}>1800 \mathrm{~s}(30 \mathrm{~min})$. The temperatures at time $=30 \mathrm{~min}(1800 \mathrm{~s})$, calculated from Eq. 5 for several different values of the parameter $x^{2} / \alpha$, are presented in Fig. 4 and Table 1.

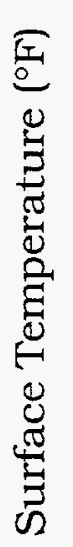

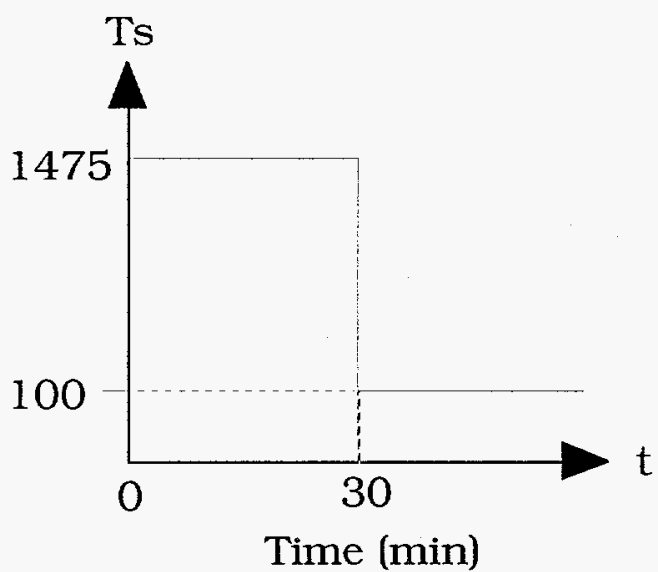

Fig. 3. Step surface temperature condition to represent a hypothetical-accident thermal test

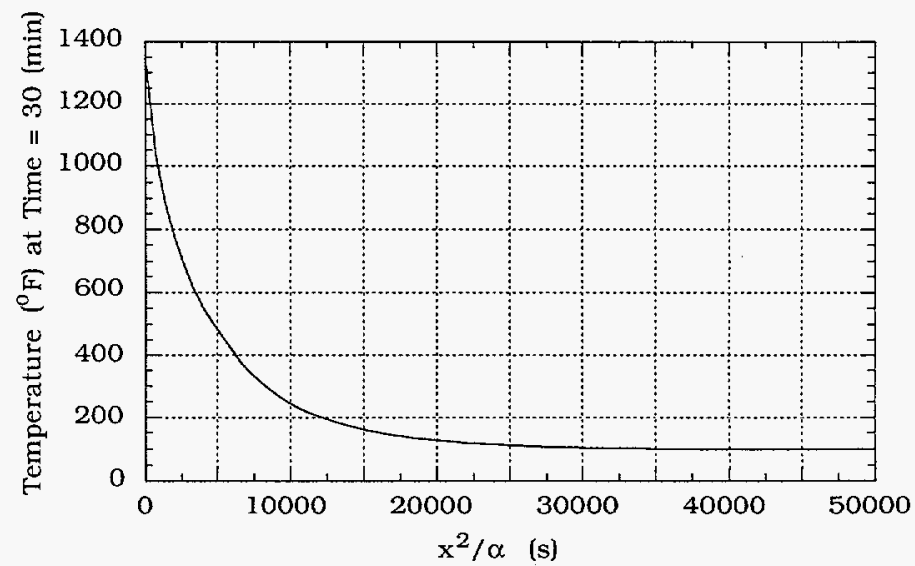

Fig. 4. Temperature at time $=30 \mathrm{~min}$ in a semi-infinite solid subjected to $1475^{\circ} \mathrm{F}$ step temperature change at the surface 
Table 1. Temperature in a semi-infinite solid at time $=30 \mathrm{~min}$ for various values of $x^{2} / \alpha$

\begin{tabular}{|c|c|c|c|}
\hline$x^{2} / \alpha(s)$ & $x / \sqrt{4 \alpha t}$ & $\operatorname{erfc}(x / \sqrt{4 \alpha t})$ & Temperature $\left({ }^{\circ} \mathrm{F}\right)$ \\
\hline 72 & 0.1 & 0.887537 & 1320.0 \\
\hline 288 & 0.2 & 0.777297 & 1169.0 \\
\hline 648 & 0.3 & 0.671373 & 1023.0 \\
\hline 1152 & 0.4 & 0.571608 & 886.00 \\
\hline 1800 & 0.5 & 0.479500 & 759.30 \\
\hline 2592 & 0.6 & 0.396144 & 644.70 \\
\hline 3528 & 0.7 & 0.322199 & 543.00 \\
\hline 4608 & 0.8 & 0.257899 & 454.60 \\
\hline 5832 & 0.9 & 0.203092 & 379.30 \\
\hline 7200 & 1.0 & 0.157299 & 316.30 \\
\hline 8712 & 1.1 & 0.119795 & 264.70 \\
\hline 10368 & 1.2 & 0.089686 & 223.30 \\
\hline 12168 & 1.3 & 0.065992 & 190.70 \\
\hline 14112 & 1.4 & 0.047715 & 165.60 \\
\hline 16200 & 1.5 & 0.033895 & 146.60 \\
\hline 18432 & 1.6 & 0.023652 & 132.50 \\
\hline 20808 & 1.7 & 0.016210 & 122.30 \\
\hline 23328 & 1.8 & 0.010909 & 115.00 \\
\hline 25992 & 1.9 & 0.007210 & 109.91 \\
\hline 28800 & 2.0 & 0.004678 & 106.43 \\
\hline 31752 & 2.1 & 0.002979 & 104.10 \\
\hline 34848 & 2.2 & 0.001863 & 102.56 \\
\hline 38088 & 2.3 & 0.001143 & 101.57 \\
\hline 41472 & 2.4 & 0.000689 & 100.95 \\
\hline 45000 & 2.5 & 0.000407 & 100.56 \\
\hline 48672 & 2.6 & 0.000236 & 100.32 \\
\hline 52488 & 2.7 & 0.000134 & 100.18 \\
\hline 56448 & 2.8 & 0.000075 & 100.10 \\
\hline 60552 & 2.9 & 0.000041 & 100.06 \\
\hline 64800 & 3.0 & 0.000022 & 100.03 \\
\hline
\end{tabular}




\subsection{MAXIMUM TEMPERATURE}

The maximum temperature in a semi-infinite solid will occur when $\partial \mathrm{T} / \partial \mathrm{t}=0$, or

$$
\begin{aligned}
& \frac{\partial}{\partial \mathrm{t}}\left[\operatorname{erfc}\left(\frac{\sqrt{\mathrm{x}^{2} / \alpha}}{2 \sqrt{\mathrm{t}}}\right)\right]-\frac{\partial}{\partial \mathrm{t}}\left[\operatorname{erfc}\left(\frac{\sqrt{\mathrm{x}^{2} / \alpha}}{2 \sqrt{\mathrm{t}-1800}}\right)\right]=0, \\
& \mathrm{t}_{\mathrm{T}_{\max }}^{3 / 2} \exp \left(\frac{-\mathrm{x}^{2} / \alpha}{4 \mathrm{t}_{\mathrm{T} \max }}\right)=\left(\mathrm{t}_{\mathrm{T} \max }-1800\right)^{3 / 2} \exp \left(\frac{-\mathrm{x}^{2} / \alpha}{4\left(\mathrm{t}_{\mathrm{T} \max }-1800\right)}\right) .
\end{aligned}
$$

Here, $t_{\text {Tmax }}$ is the time when the temperature will be maximum. Equation 8 has been solved iteratively to obtain $t_{T \max }$ for several different values of the parameter $x^{2} / \alpha$. The maximum temperature can then be obtained by substituting $t=t_{T \max }$ in the solution of diffusion Eq. 6 .

$$
\frac{\left(\mathrm{T}_{\max }-100\right)}{(1375)}=\operatorname{erfc}\left(\frac{\sqrt{\mathrm{x}^{2} / \alpha}}{2 \sqrt{\mathrm{t}_{\max }}}\right)-\operatorname{erfc}\left(\frac{\sqrt{\mathrm{x}^{2} / \alpha}}{2 \sqrt{\mathrm{t}_{\mathrm{T} \max }-1800}}\right) \text {. }
$$

The maximum temperatures, calculated from Eq. 9 for several values of $x^{2} / \alpha$, are presented in Fig. 5 and Table 2.

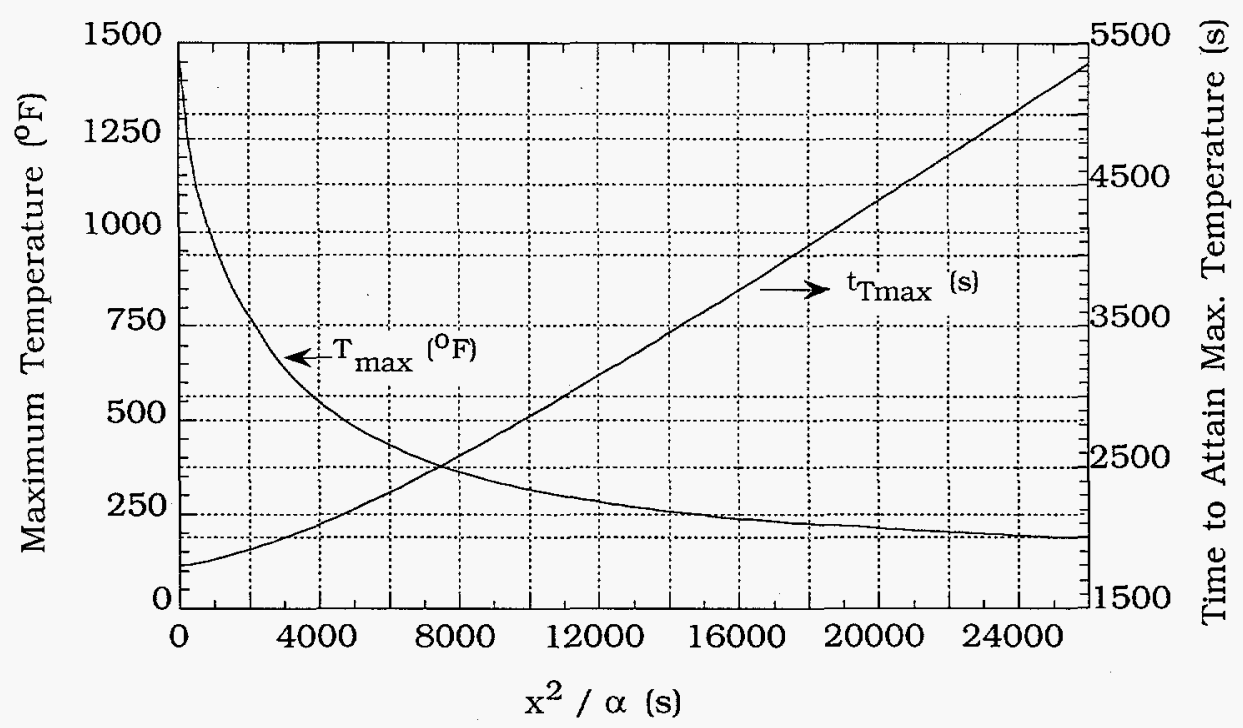

Fig. 5. Maximum temperature and time to attain maximum temperature in a semi-infinite solid subjected to $1475^{\circ} \mathrm{F}$ step temperature change at the surface 
Table 2. Maximum temperature and time to attain maximum temperature for various values of $x^{2} / \alpha$

\begin{tabular}{|c|c|c|c|}
\hline $\begin{array}{c}x^{2} / \alpha \\
\text { (s) }\end{array}$ & $\begin{array}{c}\mathrm{t}_{\mathrm{T} \max } \\
\text { (s) }\end{array}$ & $\begin{array}{l}\mathrm{t}_{\operatorname{Tmax}} \\
(\min )\end{array}$ & $\begin{array}{c}\mathrm{T}_{\max } \\
\left({ }^{\circ} \mathrm{F}\right)\end{array}$ \\
\hline 600 & 1822 & 30.37 & 1041 \\
\hline 800 & 1832 & 30.53 & 981 \\
\hline 1,000 & 1843 & 30.72 & 928 \\
\hline 1,200 & 1855 & 30.92 & 882 \\
\hline 1,400 & 1868 & 31.13 & 841 \\
\hline 1,600 & 1881 & 31.35 & 805 \\
\hline 1,800 & 1895 & 31.58 & 772 \\
\hline 2,000 & 1910 & 31.83 & 742 \\
\hline 2,500 & 1950 & 32.50 & 677 \\
\hline 3,000 & 1994 & 33.23 & 624 \\
\hline 3,500 & 2041 & 34.02 & 578 \\
\hline 4,000 & 2091 & 34.85 & 539 \\
\hline 4,500 & 2144 & .35 .73 & 506 \\
\hline 5,000 & 2200 & 36.67 & 476 \\
\hline 5,500 & 2258 & 37.63 & 452 \\
\hline 6,000 & 2319 & 38.65 & 429 \\
\hline 7,000 & 2445 & 40.75 & 391 \\
\hline 8,000 & 2577 & 42.95 & 361 \\
\hline 9,000 & 2715 & 45.25 & 336 \\
\hline 10,000 & 2856 & 47.60 & 314 \\
\hline 11,000 & 3001 & 50.02 & 297 \\
\hline 12,000 & 3149 & 52.48 & 282 \\
\hline 13,000 & 3300 & 55.00 & 269 \\
\hline 14,000 & 3452 & 57.53 & 258 \\
\hline 15,000 & 3606 & 60.10 & 248 \\
\hline 16,000 & 3761 & 62.68 & 240 \\
\hline 17,000 & 3918 & 65.30 & 232 \\
\hline 18,000 & 4075 & 67.92 & 226 \\
\hline 19,000 & 4234 & 70.57 & 219 \\
\hline 20,000 & 4393 & 73.22 & 213 \\
\hline
\end{tabular}




\section{TEMPERATURE IN AN INFINITE CIRCULAR CYLINDER ( $(=0)$}

The analysis of temperature in an infinite circular cylinder of radius $R$, with no internal heat source and step change in the surface temperature, is presented here.

\subsection{GOVERNING EQUATION}

The governing equation for temperature in an infinite circular cylinder is

$$
\frac{\partial^{2} \mathrm{~T}}{\partial \mathrm{r}^{2}}+\frac{1}{\mathrm{r}} \frac{\partial \mathrm{T}}{\partial \mathrm{r}}-\frac{1}{\alpha} \frac{\partial \mathrm{T}}{\partial \mathrm{t}}=0
$$

Where $\mathrm{T}, \mathrm{r}(=\mathrm{R}-\mathrm{x}), \mathrm{x}, \alpha$, and $\mathrm{t}$ are the temperature, radius, radial distance from the surface, thermal diffusivity, and time, respectively.

\subsection{SOLUTION}

The one-dimensional analytical solution of Eq. 10 for an infinite circular cylinder, initially at temperature $T_{0}$ and subjected to step surface temperatures $T_{s 1}$ for a time $\leq t_{1}$, and $T_{s 2}$ for a time $>t_{1}$, i.e,

$$
\begin{array}{ll}
\mathrm{T}=\mathrm{T}_{0} & \text { for } \mathrm{t}=0, \\
\mathrm{~T}_{\mathrm{r}^{*}=1}=\mathrm{T}_{\mathrm{S} 1} & \text { for } 0<\mathrm{t} \leq \mathrm{t}_{1}, \\
\mathrm{~T}_{\mathrm{r}^{*}=1}=\mathrm{T}_{\mathrm{S} 2} ; & \text { for } \mathrm{t}>\mathrm{t}_{1},
\end{array}
$$

as given by Eq. 8 in Section 7.6 of Carslaw and Jaeger, ${ }^{2}$ is

$$
\frac{\left(T-T_{0}\right)}{\left(T_{s 1}-T_{0}\right)}=1-2 \sum_{n=1}^{\infty} \exp \left(\frac{-\beta_{n}^{2} \alpha t}{R^{2}}\right) \frac{J_{0}\left(r^{*} \beta_{n}\right)}{\beta_{n} J_{1}\left(\beta_{n}\right)},
$$

for $\mathrm{t} \leq \mathrm{t}_{1}$, and

$$
\frac{\left(T-T_{0}\right)}{\left(T_{s 1}-T_{0}\right)}=1-2 \sum_{n=1}^{\infty} \exp \left(\frac{-\beta_{n}^{2} \alpha t}{R^{2}}\right) \frac{J_{0}\left(r^{*} \beta_{n}\right)}{\beta_{n} J_{1}\left(\beta_{n}\right)}
$$




$$
+\frac{\left(T_{s 2}-T_{s 1}\right)}{\left(T_{s 1}-T_{0}\right)} \quad\left(1-2 \sum_{n=1}^{\infty} \exp \left(\frac{-\beta_{n}^{2} \alpha\left(t-t_{1}\right)}{R^{2}}\right) \frac{J_{0}\left(r^{*} \beta_{n}\right)}{\beta_{n} J_{1}\left(\beta_{n}\right)}\right)
$$

for $t>t_{1}$. In Eqs. 13 and $14, R, r^{*}(=r / R)$, and $J_{n}(\beta)$ are the radius of the cylinder, dimensionless radial distance, and Bessel function of the first kind of order $n$, respectively, and $\pm\left(\beta_{n}\right), n=1,2, \ldots$, are the roots of the Bessel function $J_{0}(\beta)=0$. Let

$$
\psi_{n}=\exp \left(\frac{-\beta_{n}^{2} \alpha t}{R^{2}}\right) \frac{J_{0}\left(r^{*} \beta_{n}\right)}{\beta_{n} J_{1}\left(\beta_{n}\right)},
$$

and

$$
\psi_{n}^{\prime}=\exp \left(\frac{-\beta_{n}^{2} \alpha\left(t-t_{1}\right)}{R^{2}}\right) \frac{J_{0}\left(r^{*} \beta_{n}\right)}{\beta_{n} J_{1}\left(\beta_{n}\right)} .
$$

Eqs. 15 and 16 simplify to

$$
T=T_{s 1}-2\left(T_{s 1}-T_{0}\right) \sum_{n=1}^{\infty} \psi_{n}
$$

for $\mathrm{t} \leq \mathrm{t}_{1}$ and

$$
\mathrm{T}=\mathrm{T}_{\mathrm{s} 2}-2\left(\mathrm{~T}_{\mathrm{s} 1}-\mathrm{T}_{0}\right) \sum_{\mathrm{n}=1}^{\infty} \psi_{\mathrm{n}}-2\left(\mathrm{~T}_{\mathrm{s} 2}-\mathrm{T}_{\mathrm{s} 1}\right) \sum_{\mathrm{n}=1}^{\infty} \psi_{\mathrm{n}}^{\prime}
$$

for $t>t_{1}$.

\subsection{HYPOTHETICAL-ACCIDENT CONDITIONS}

The solution of Eq. 10 for surface temperature conditions during the hypothetical-accident shown in Fig. 2, i.e., $\mathrm{T}=\mathrm{T}_{0}=100^{\circ} \mathrm{F}$, for $t=0, \mathrm{~T}_{\mathrm{r}^{*}=1}=$ $\mathrm{T}_{\mathrm{s} 1}=1475^{\circ} \mathrm{F}$ for $0<\mathrm{t} \leq 1800 \mathrm{~s}$, and $\mathrm{T}_{\mathrm{r}^{*}=1}=\mathrm{T}_{\mathrm{s} 2}=100^{\circ} \mathrm{F}$ for $\mathrm{t}>1800 \mathrm{~s}$ is

$$
T=1475-2(1375) \sum_{n=1}^{\infty} \psi_{n}
$$

for $\mathrm{t} \leq 1800 \mathrm{~s}(30 \mathrm{~min})$ and

$$
T=100-2(1375) \sum_{n=1}^{\infty} \psi_{n}+2(1375) \sum_{n=1}^{\infty} \psi_{n}^{\prime}
$$


for $\mathrm{t}>1800 \mathrm{~s}$ (30 min).

The temperatures at time $=30 \mathrm{~min}(1800 \mathrm{~s})$, calculated from Eq. 19 for several values of the parameters $R^{2} / \alpha$ and $r^{*}(=r / R)$, are presented in Fig. 6 and Table 3.

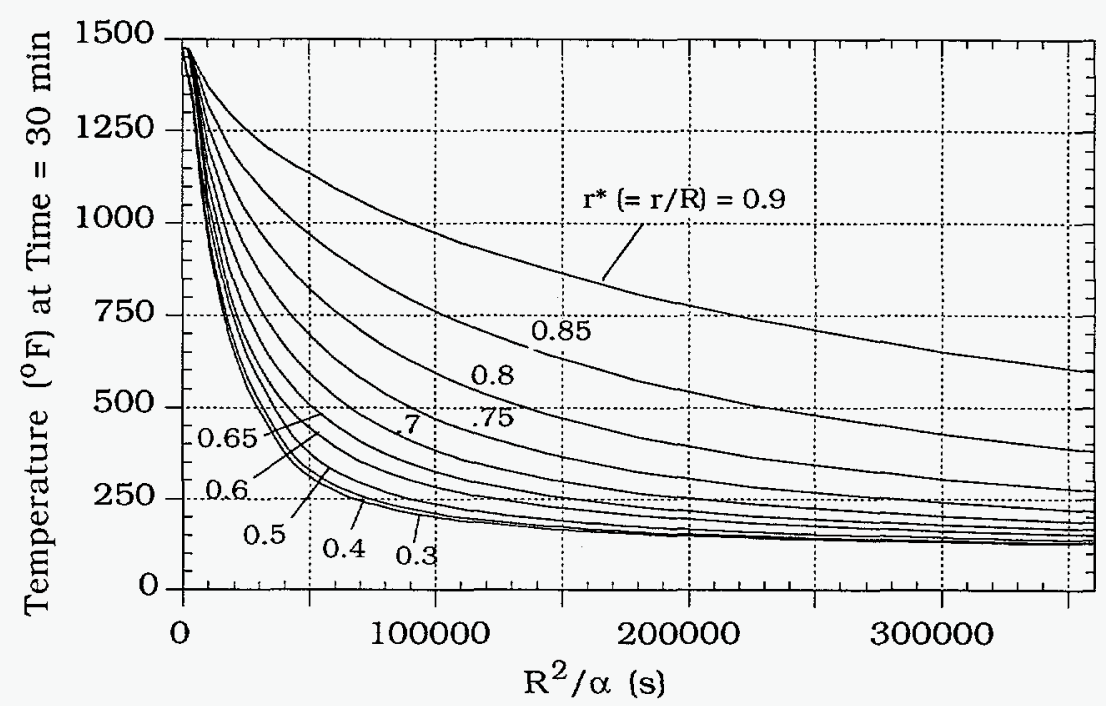

Fig. 6. Temperature at time $=30 \mathrm{~min}$ in an infinite cylinder subjected to $1475^{\circ} \mathrm{F}$ step temperature change at the surface

\subsection{MAXIMUM TEMPERATURE}

The maximum temperature in a semi-infinite cylinder will occur when $\partial \mathrm{T} / \partial \mathrm{t}=0$ or

$$
\sum_{n=1}^{\infty} \exp \left(\frac{-\beta_{n}^{2} \alpha\left(t_{\operatorname{Tax}}-1800\right)}{R^{2}}\right) \frac{\beta_{n} \alpha J_{0}\left(r^{*} \beta_{n}\right)}{R^{2} J_{1}\left(\beta_{n}\right)}=\sum_{n=1}^{\infty} \exp \left(\frac{-\beta_{n}^{2} \alpha t_{\operatorname{Tax}}}{R^{2}}\right) \frac{\beta_{n} \alpha J_{0}\left(r^{*} \beta_{n}\right)}{R^{2} J_{1}\left(\beta_{n}\right)}
$$

Here, $t_{T \max }$ is the time when the temperature will be maximum. Equation 21 has been solved iteratively to obtain $t_{\text {Tmax }}$ for several values of the parameters $r^{*}(=r / R)$ and $R^{2} / \alpha$.

The maximum temperature can be obtained by substituing $t=t_{T \max }$ in Eq. 20. The maximum temperature and time when the maximum temperature occurs have been calculated for several values of the parameters $\mathrm{r}^{*}(=\mathrm{r} / \mathrm{R})$ and $\mathrm{R}^{2} / \alpha$. The results are presented in Figs. 7 and 8 and Tables 4 and 5 . 
Table 3. Temperature in an infinite cylinder at time $=30 \mathrm{~min}$ for various values of $\mathrm{R}^{2} / \alpha$ and $r^{*}(=r / R)$

\begin{tabular}{|c|c|c|c|c|c|c|}
\hline \multirow[b]{2}{*}{$\mathrm{R}^{2} / \alpha(\mathrm{s})$} & \multirow[b]{2}{*}{$\alpha t / R^{2}$} & \multicolumn{5}{|c|}{$\mathrm{r}^{*}$} \\
\hline & & 0.3 & 0.4 & 0.5 & 0.6 & 0.65 \\
\hline 0 & $\infty$ & 1475 & 1475 & 1475 & 1475 & 1475 \\
\hline 2250 & 0.8000 & 1456 & 1458 & 1461 & 1463 & 1465 \\
\hline 3000 & 0.6000 & 1415 & 1421 & 1429 & 1438 & 1442 \\
\hline 5000 & 0.3600 & 1235 & 1260 & 1291 & 1326 & 1344 \\
\hline 18000 & 0.1000 & 424.7 & 516.9 & 635.9 & 779.6 & 859.4 \\
\hline 24000 & 0.0750 & 290.7 & 376.4 & 495.1 & 648.0 & 736.7 \\
\hline 30000 & 0.0600 & 214.9 & 287.7 & 397.0 & 548.8 & 641.1 \\
\hline 36000 & 0.0500 & 170.5 & 229.4 & 326.1 & 471.3 & 563.9 \\
\hline 40000 & 0.0450 & 151.3 & 201.6 & 289.5 & 428.4 & 520.1 \\
\hline 50000 & 0.0360 & 123.5 & 156.3 & 223.2 & 344.3 & 430.9 \\
\hline 60000 & 0.0300 & 111.0 & 131.7 & 181.2 & 283.7 & 363.3 \\
\hline 72000 & 0.0250 & 104.5 & 116.1 & 149.8 & 231.8 & 301.9 \\
\hline 120000 & 0.0150 & 100.1 & 101.2 & 107.6 & 137.3 & 174.2 \\
\hline 180000 & 0.0100 & 100.0 & 100.0 & 100.8 & 108.3 & 122.8 \\
\hline \multirow[t]{2}{*}{360000} & 0.0050 & 100.0 & 100.0 & 100.0 & 100.0 & 100.8 \\
\hline & \multicolumn{6}{|c|}{$\mathrm{r}^{*}$} \\
\hline $\mathrm{R}^{2} / \alpha(\mathrm{s})$ & $\alpha t / R^{2}$ & 0.7 & 0.75 & 0.8 & 0.85 & 0.9 \\
\hline 0 & $\infty$ & 1475 & 1475 & 1475 & 1475 & 1475 \\
\hline 5000 & 0.3600 & 1363 & 1382 & 1401 & 1420 & 1439 \\
\hline 18000 & 0.1000 & 943.4 & 1031 & 1120 & 1211 & 1301 \\
\hline 30000 & 0.0600 & 743.6 & 855.2 & 974.1 & 1098 & 1225 \\
\hline 40000 & 0.0450 & 626.9 & 748.0 & 881.7 & 1025 & 1175 \\
\hline 50000 & 0.0360 & 536.8 & 662.1 & 805.2 & 963.1 & 1131 \\
\hline 60000 & 0.0300 & 465.3 & 591.1 & 740.0 & 908.9 & 1093 \\
\hline 72000 & 0.0250 & 397.2 & 520.7 & 673.0 & 851.7 & 1051 \\
\hline 90000 & 0.0200 & 320.7 & 437.0 & 589.6 & 777.9 & 996.2 \\
\hline 120000 & 0.0150 & 237.4 & 337.3 & 482.7 & 677.7 & 918.4 \\
\hline 144000 & 0.0125 & 195.3 & 281.3 & 417.3 & 612.3 & 865.1 \\
\hline 180000 & 0.0100 & 155.9 & 222.7 & 342.3 & 531.5 & 795.9 \\
\hline 225000 & 0.0080 & 129.2 & 176.5 & 275.3 & 452.0 & 722.7 \\
\hline 300000 & 0.0060 & 110.2 & 135.8 & 204.5 & 355.2 & 624.1 \\
\hline 360000 & 0.0050 & 104.4 & 119.8 & 170.0 & 299.5 & 560.3 \\
\hline
\end{tabular}




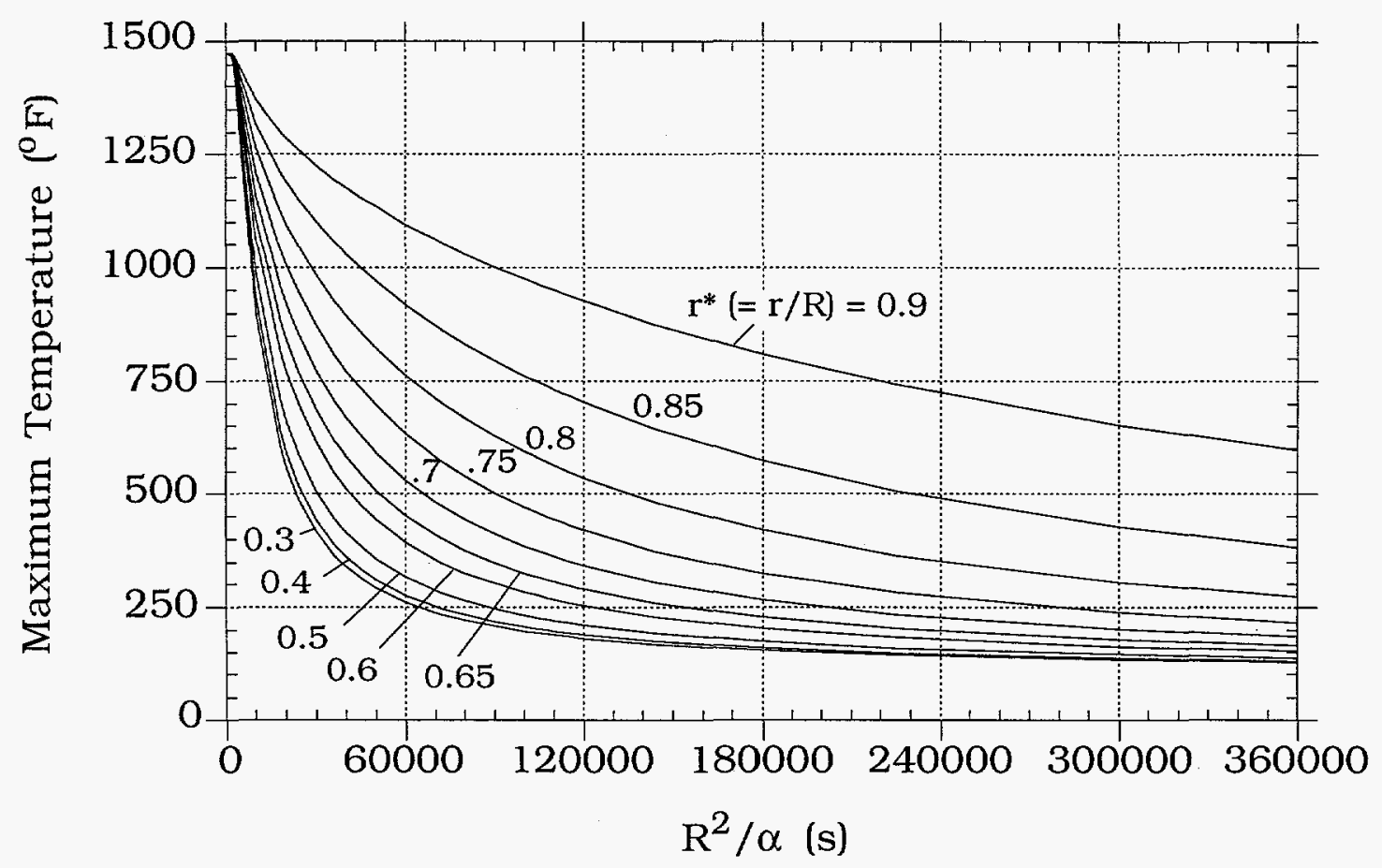

Fig. 7. Maximum temperature in an infinite cylinder subjected to $1475^{\circ} \mathrm{F}$ step temperature change at the surface

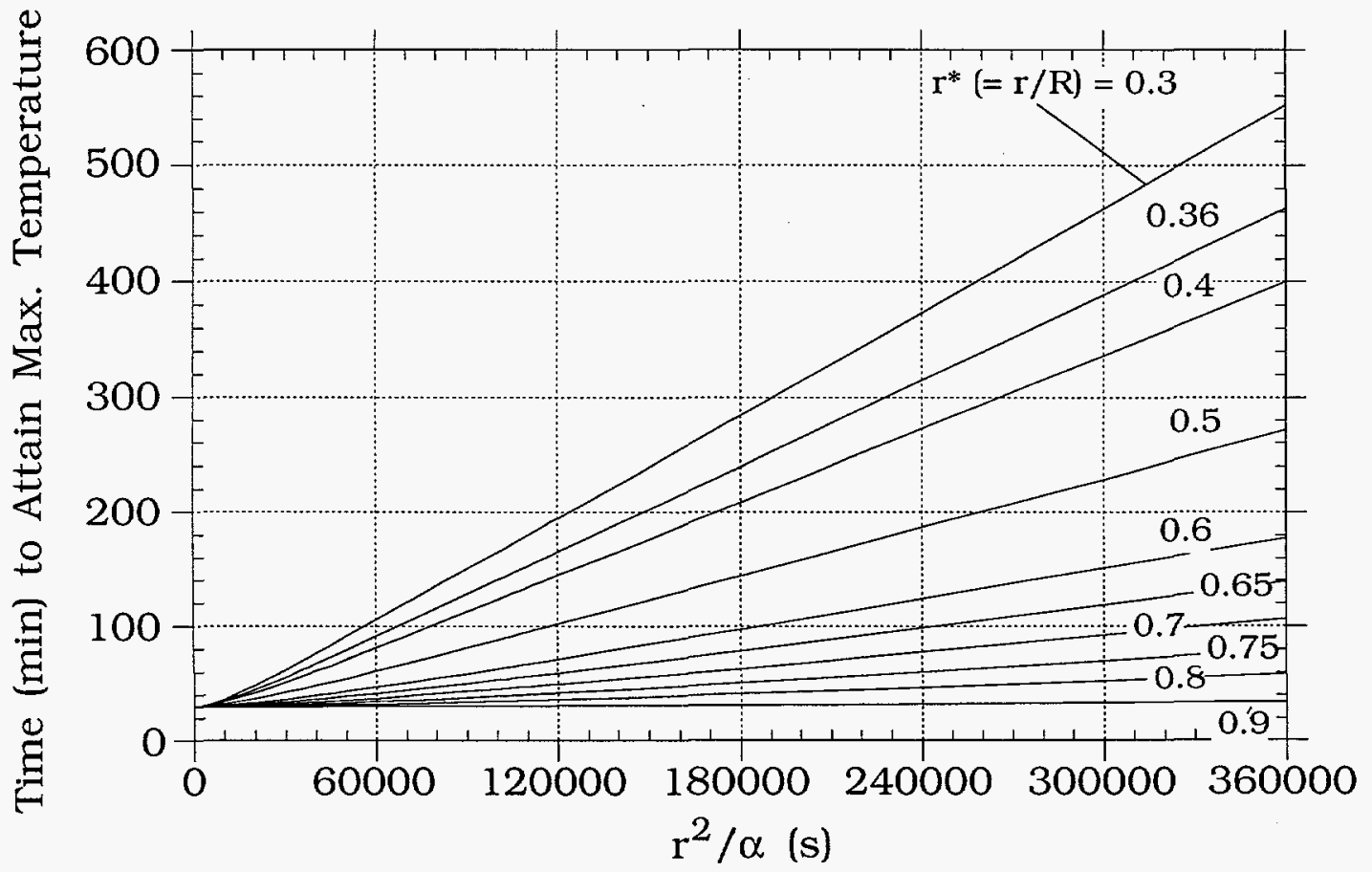

Fig. 8. Time to attain maximum temperature in an infinite cylinder subjected to $1475^{\circ} \mathrm{F}$ step temperature change at the surface 
Table 4. Maximum temperature in an infinite cylinder for various values of $R^{2} / \alpha$ and $r^{*}(=r / R)$

\begin{tabular}{|c|c|c|c|c|c|c|}
\hline \multirow{2}{*}{$\begin{array}{c}\mathrm{R}^{2} / \alpha \\
\text { (s) }\end{array}$} & \multicolumn{6}{|c|}{$\mathrm{r}^{*}$} \\
\hline & 0.3 & 0.36 & 0.4 & 0.5 & 0.6 & 0.65 \\
\hline 0 & 1475.00 & 1475.00 & 1475.00 & 1475.00 & 1475.00 & 1475.00 \\
\hline 2250 & 1457.59 & 1458.41 & 1459.07 & 1461.08 & 1463.54 & 1464.89 \\
\hline 3000 & 1420.48 & 1422.89 & 1428.87 & 1431.03 & 1438.69 & 1442.96 \\
\hline 5000 & 1263.00 & 1271.11 & 1278.10 & 1300.93 & 1330.44 & 1347.15 \\
\hline 18000 & 603.08 & 619.58 & 637.02 & 707.13 & 815.42 & 882.67 \\
\hline 24000 & 488.30 & 502.80 & 518.85 & 586.81 & 698.08 & 770.40 \\
\hline 30000 & 415.02 & 427.62 & 441.95 & 504.78 & 612.45 & 685.42 \\
\hline 36000 & 364.59 & 375.59 & 388.33 & 445.55 & 547.12 & 618.51 \\
\hline 40000 & 338.95 & 349.06 & 360.87 & 414.53 & 511.59 & 581.26 \\
\hline 50000 & 292.18 & 300.54 & 310.45 & 356.35 & 442.36 & 506.77 \\
\hline 60000 & 260.62 & 267.71 & 276.19 & 315.95 & 392.23 & 451.14 \\
\hline 72000 & 234.12 & 240.11 & 247.31 & 281.38 & 347.98 & 400.80 \\
\hline 120000 & 180.72 & 184.38 & 188.82 & 210.14 & 253.19 & 289.05 \\
\hline 180000 & 153.86 & 156.32 & 159.31 & 173.32 & 203.14 & 228.14 \\
\hline \multirow[t]{3}{*}{360000} & 126.95 & 128.18 & 129.68 & 136.95 & 151.89 & 164.75 \\
\hline & \multicolumn{6}{|c|}{$r^{*}$} \\
\hline & 0.7 & 0.75 & 0.8 & 0.85 & 0.9 & \\
\hline 0 & 1475.00 & 1475.00 & 1475.00 & 1475.00 & 1475.00 & \\
\hline 5000 & 1466.31 & 1467.77 & 1469.24 & 1470.71 & 1471.83 & \\
\hline 18000 & 1447.42 & 1453.02 & 1456.72 & 1461.42 & 1465.72 & \\
\hline 30000 & 1364.80 & 1383.13 & 1401.83 & 1420.63 & 1438.92 & \\
\hline 40000 & 957.41 & 1038.30 & 1123.77 & 1212.02 & 1300.94 & \\
\hline 50000 & 771.84 & 871.19 & 981.88 & 1101.24 & 1225.62 & \\
\hline 60000 & 705.56 & 808.64 & 926.64 & 1056.77 & 1194.73 & \\
\hline 72000 & 667.76 & 772.12 & 893.71 & 1029.83 & 1175.80 & \\
\hline 90000 & 626.22 & 731.18 & 856.13 & 998.62 & 1153.65 & \\
\hline 120000 & 589.92 & 694.65 & 821.92 & 969.76 & 1133.92 & \\
\hline 144000 & 529.60 & 632.16 & 761.77 & 917.79 & 1094.96 & \\
\hline 180000 & 473.22 & 571.48 & 701.00 & 863.47 & 1054.26 & \\
\hline 225000 & 341.37 & 419.18 & 535.20 & 702.47 & 925.47 & \\
\hline 300000 & 265.61 & 324.15 & 418.97 & 573.32 & 809.14 & \\
\hline 360000 & 184.40 & 216.33 & 272.45 & 380.13 & 595.31 & \\
\hline
\end{tabular}


Table 5. Time ( $\mathrm{min}$ ) to attain maximum temperature in an infinite cylinder for various values of $\mathrm{R}^{2} / \alpha$ and $r^{*}(=r / R)$

\begin{tabular}{|c|c|c|c|c|c|c|}
\hline \multirow{2}{*}{$\begin{array}{c}\mathrm{R}^{2} / \alpha \\
\text { (s) }\end{array}$} & \multicolumn{6}{|c|}{$\mathrm{r}^{*}$} \\
\hline & 0.3 & 0.36 & 0.4 & 0.5 & 0.6 & 0.65 \\
\hline 0 & 30.00 & 30.00 & 30.00 & 30.00 & 30.00 & 30.00 \\
\hline 2250 & 30.58 & 30.48 & 30.41 & 30.27 & 30.16 & 30.12 \\
\hline 3000 & 30.95 & 30.78 & 30.67 & 30.43 & 30.25 & 30.18 \\
\hline 5000 & 32.22 & 31.80 & 31.53 & 30.96 & 30.55 & 30.39 \\
\hline 18000 & 46.23 & 42.84 & 40.63 & 36.11 & 33.16 & 32.16 \\
\hline 24000 & 54.20 & 49.22 & 45.89 & 39.12 & 34.71 & 33.20 \\
\hline 30000 & 62.53 & 55.94 & 51.47 & 42.41 & 36.44 & 34.38 \\
\hline 36000 & 71.03 & 62.88 & 57.28 & 45.91 & 38.33 & 35.66 \\
\hline 40000 & 76.78 & 67.57 & 61.22 & 48.34 & 39.66 & 36.57 \\
\hline 50000 & 91.28 & 79.51 & 71.31 & 54.63 & 43.17 & 39.01 \\
\hline 60000 & 105.93 & 91.61 & 81.57 & 61.14 & 46.92 & 41.64 \\
\hline 72000 & 123.59 & 106.24 & 94.04 & 69.15 & 51.62 & 44.98 \\
\hline 120000 & 194.71 & 165.39 & 144.63 & 102.19 & 71.61 & 59.58 \\
\hline 180000 & 283.98 & 239.80 & 208.45 & 144.30 & 97.68 & 79.05 \\
\hline \multirow[t]{2}{*}{360000} & 552.24 & 463.64 & 400.67 & 271.79 & 177.60 & 139.55 \\
\hline & \multicolumn{4}{|c|}{$\mathrm{r}^{*}$} & & \\
\hline $\mathrm{R}^{2} / \alpha(\mathrm{s})$ & 0.7 & 0.75 & 0.8 & 0.85 & 0.9 & \\
\hline 0 & 30.00 & 30.00 & 30.00 & 30.00 & 30.00 & \\
\hline 5000 & 30.08 & 30.05 & 30.03 & 30.02 & 30.01 & \\
\hline 18000 & 30.13 & 30.08 & 30.05 & 30.03 & 30.02 & \\
\hline 30000 & 30.26 & 30.17 & 30.10 & 30.05 & 30.03 & \\
\hline 40000 & 31.41 & 30.86 & 30.48 & 30.23 & 30.10 & \\
\hline 50000 & 32.83 & 31.70 & 30.93 & 30.44 & 30.18 & \\
\hline 60000 & 33.64 & 32.17 & 31.18 & 30.55 & 30.22 & \\
\hline 72000 & 34.22 & 32.52 & 31.36 & 30.63 & 30.25 & \\
\hline 90000 & 34.99 & 32.97 & 31.60 & 30.74 & 30.28 & \\
\hline 120000 & 35.79 & 33.44 & 31.84 & 30.85 & 30.31 & \\
\hline 144000 & 37.51 & 34.45 & 32.37 & 31.08 & 30.39 & \\
\hline 180000 & 39.71 & 35.77 & 33.06 & 31.38 & 30.48 & \\
\hline 225000 & 49.66 & 41.88 & 36.31 & 32.79 & 30.93 & \\
\hline 300000 & 63.37 & 50.70 & 41.20 & 34.95 & 31.59 & \\
\hline 360000 & 107.04 & 80.01 & 58.59 & 43.19 & 34.18 & \\
\hline
\end{tabular}




\section{EXAMPLE}

To illustrate the simplicity of the estimating procedure, the Mound 9859 tritium trap package is used as an example. To further show that the procedure provides a conservative prediction, the results obtained from the example are compared with results obtained with a computer solution of a very detailed numerical model. Although the example selected has no internal heat source, i.e., $\mathrm{T}_{\max \text {-estimation }}=\mathrm{T}_{\max \text {-analytic, } \mathrm{q}=0 \text {, the qualitative }}$ arguments and mathematical analysis, presented later, will show that the estimating procedure is also applicable to a package with an internal heat source.

\subsection{MOUND 9859 TRITIUM TRAP PACKAGE}

The Mound 9859 tritium trap package, shown in Fig. 9a, is a cylindrical package designed to transport Type-B quantities of solid uranium tritide. The package is constructed to the requirements of the U.S. Department of Transportation Specification 6M for metal packaging. The trap provides the primary containment of the tritium. The inner vessel provides the secondary containment. The outer container is a stainless steel drum, 15 in. in diameter and $18 \mathrm{in}$. high, with lid, gasket, and bolted locking ring. The Celotex spacers between the drum and the inner container provide impact and thermal protection.

\subsection{TEMPERATURE ESTIMATION}

Two locations, shown in Fig. 9b, are selected as the positions on the surface of the inner vessel for estimating the maximum temperature during a hypothetical-accident thermal test. Location $A$, which requires the plane surface solution (presented in Section 3), is 3.1 in. away from the top plane surface. Location $B$, which requires the cylindrical surface solution (presented in Section 4), is 3.7 in. away from the outer cylindrical surface. The radius of the outer cylindrical surface is $5.83 \mathrm{in}$. The thermal diffusivity values of Celotex for the example are taken to be $3.77 \times 10^{-4}$ and $1.17 \times 10^{-3}$ (in. ${ }^{2} / \mathrm{s}$ ). These two values, one very high and one very low, were selected to demonstrate that the method is applicable over a wide range of parameter values.

The geometrical and physical parameters, $\left(x^{2} / \alpha\right)$ for Location $A$, and $\left(R^{2} / \alpha\right)$ and $r^{*}(=r / R)$ for Location $B$, are calculated first. The maximum temperatures $T_{\text {max-estimation, } q=0}$ for these locations are then read directly from the constructed curves shown in Figs. 10 and 11 . The estimated maximum temperatures $T_{\text {max-estimation, } \mathrm{q}=0}$ are presented in Table 6. 


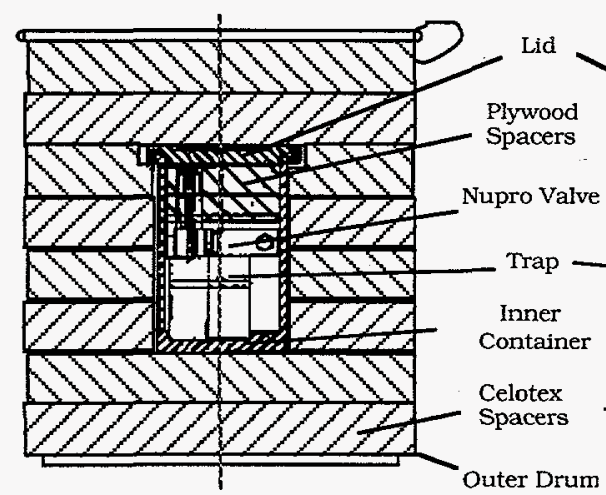

(a)

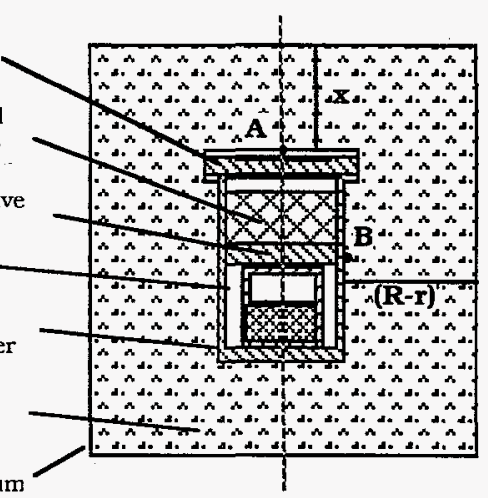

(b)

Fig. 9. Mound 9859 tritium trap package (a) actual, (b) computer model

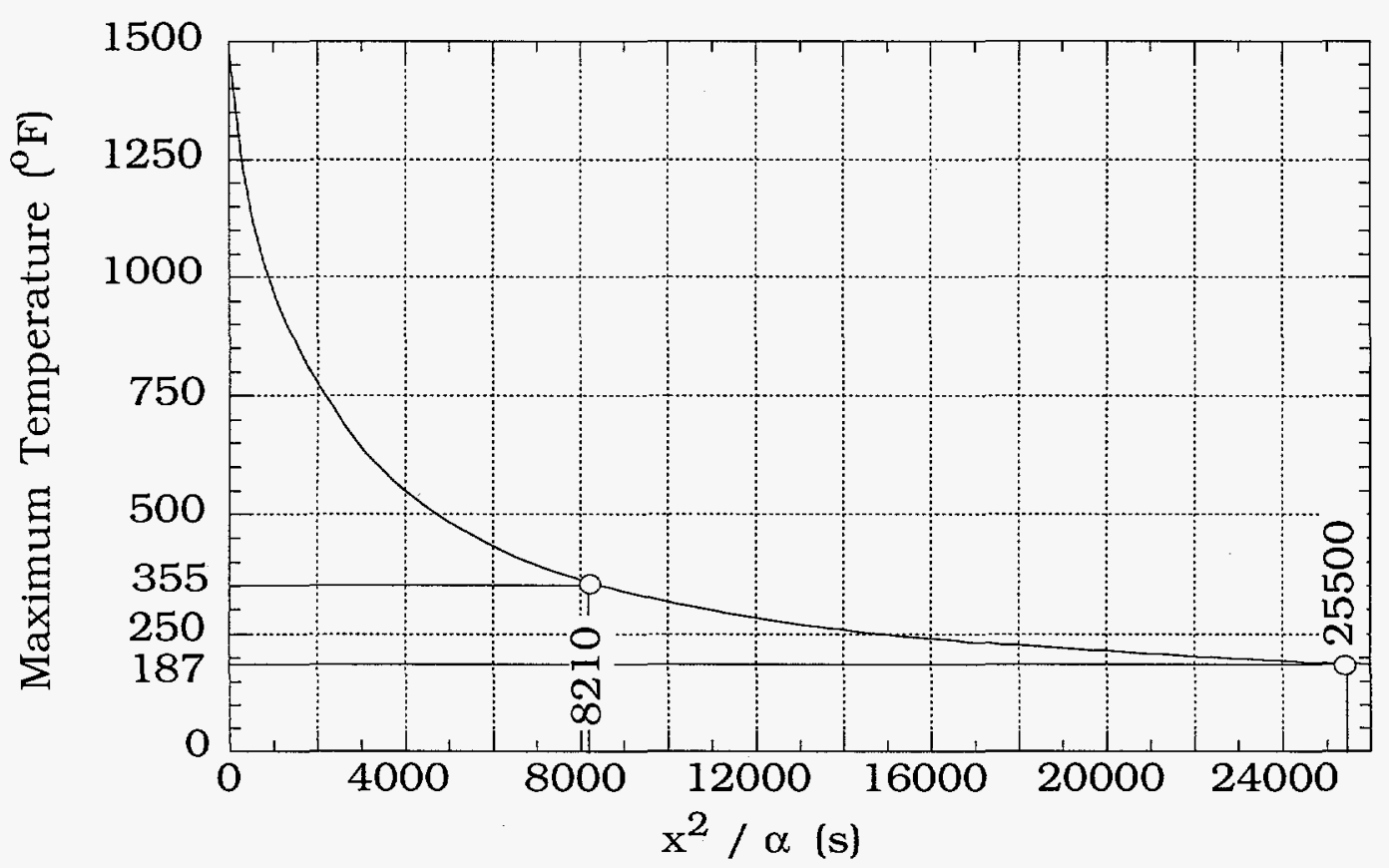

Fig. 10. Maximum temperature at Location A in the Mound 9859 tritium trap package, estimated from Fig. 5 


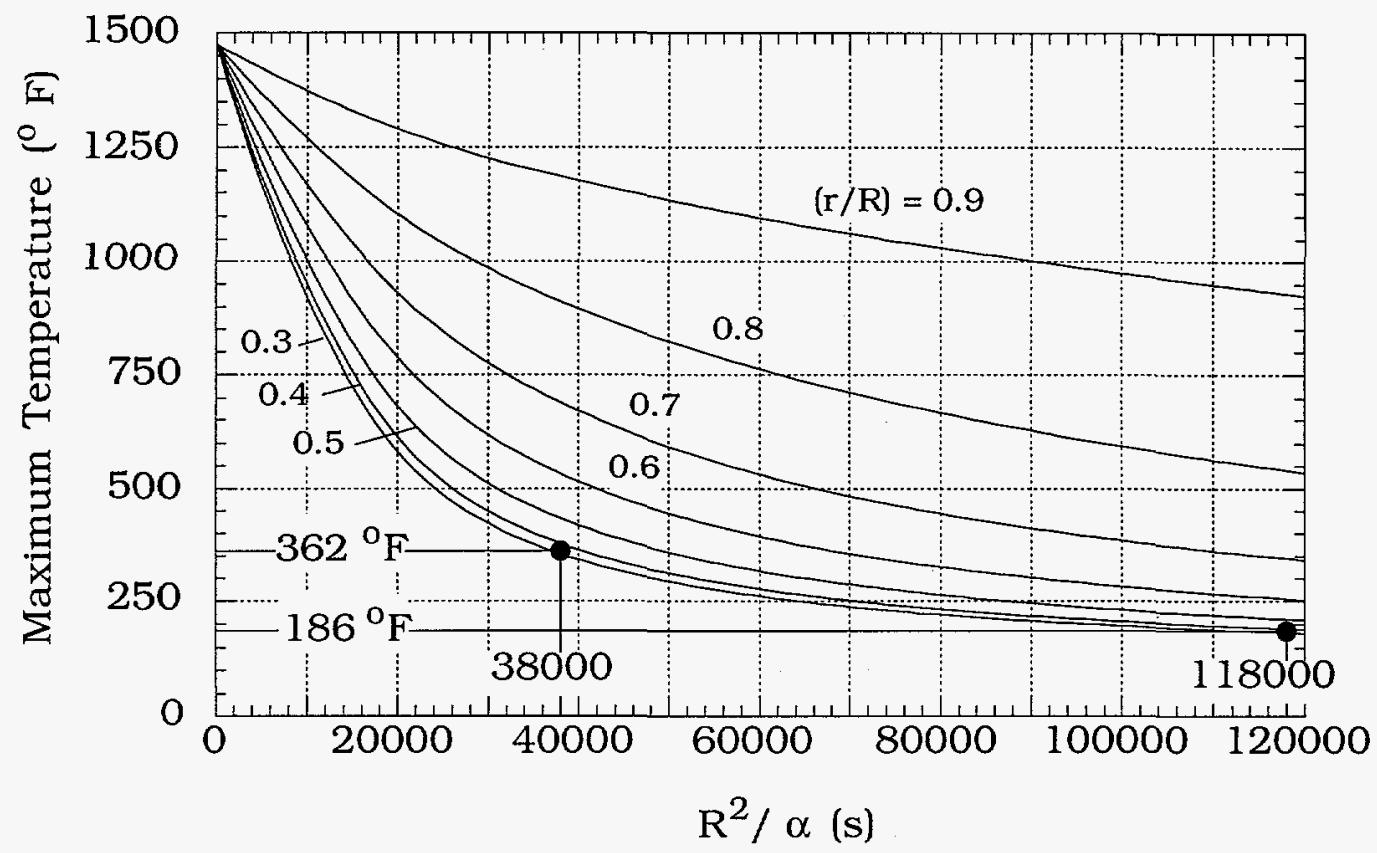

Fig. 11. Maximum temperature at Location $B$ in the Mound 9859 tritium trap package, estimated from Fig. 7

Table 6. Maximum temperatures at Locations A and B in Fig. $9 b$

\begin{tabular}{ccccc}
\hline & $\begin{array}{c}\text { Selected High } \\
\text { and Low } \\
\text { Thermal } \\
\text { Diffusivity } \\
\alpha\left(\text { in. }{ }^{2} / \mathrm{s}\right)\end{array}$ & $\begin{array}{c}\mathrm{x}^{2} / \alpha(\mathrm{s}) \\
\text { or } \\
\mathrm{R}^{2} / \alpha(\mathrm{s})^{\mathrm{a}}\end{array}$ & $\begin{array}{c}\text { Estimated } \\
\mathrm{T}_{\max }\left({ }^{\circ} \mathrm{F}\right)^{\mathrm{b}}\end{array}$ & $\begin{array}{c}\text { Predicted } \\
\mathrm{T}_{\max }\left({ }^{\circ} \mathrm{F}\right)^{\mathrm{c}}\end{array}$ \\
\hline \multirow{2}{*}{$\mathrm{A}^{\mathrm{d}}$} & $3.77 \times 10^{-4}$ & $2.55 \times 10^{4}$ & 188 & 170 \\
& $1.17 \times 10^{-3}$ & $8.21 \times 10^{3}$ & 355 & 339 \\
$\mathrm{~B}^{\mathrm{d}}$ & $3.77 \times 10^{-4}$ & $1.18 \times 10^{5}$ & 186 & 158 \\
& $1.17 \times 10^{-3}$ & $3.80 \times 10^{4}$ & 362 & 289 \\
\hline
\end{tabular}

${ }^{\mathrm{a}} \mathrm{X}^{2} / \alpha$ applies to Location $\mathrm{A}, \mathrm{R}^{2} / \alpha$ applies to Location $\mathrm{B}$.

bestimated from Fig. 5 for Location A, from Fig. 7 for Location B.

cPredicted by numerical simulation.

${ }^{\mathrm{d}}$ For Location $\mathrm{A}, \mathrm{x}=3.1$ in.; for Location $\mathrm{B}, \mathrm{r}=2.41$ in.; and $\mathrm{r} / \mathrm{R}=0.36$. 


\subsection{NUMERICAL SOLUTION}

To show that the procedure provides a conservative estimate, a very detailed numerical simulation of the Mound 9859 package under hypothetical-accident thermal-test conditions was performed. The computer model of the package for the numerical simulation is shown in Fig. 9b. The HEATING module (version 6.0) of the SCALE 3.0 computer code was used for the simulation. The maximum temperatures at Locations $\mathrm{A}$ and $\mathrm{B}$, predicted with the computer solution, are presented in Table 6 .

\subsection{COMPARISON OF PREDICTED AND ESTIMATED MAXIMUM TEMPERATURES}

The maximum temperatures at Locations $\mathrm{A}$ and $\mathrm{B}$ predicted by the estimating procedure and by the numerical simulation are presented in Table 6. Comparison shows that the temperatures of the estimating procedure are higher than those of the numerical simulation. Therefore, the present procedure provides conservative estimates when compared with values that are predicted by a very detailed numerical simulation.

\section{TEMPERATURE IN AN INFINITE CIRCULAR CYLINDER $(Q \neq 0)$}

The analytical solution for temperature in a cylinder with an internal heat source, presented here, is not used explicitly in the estimating procedure. However, the solution provides a mathematical argument to affirm that the estimating procedure is conservative.

\subsection{GOVERNING EQUATION}

The governing equation for temperature in an infinite circular cylinder is

$$
\frac{\partial^{2} \mathrm{~T}}{\partial \mathrm{r}^{2}}+\frac{1}{\mathrm{r}} \frac{\partial \mathrm{T}}{\partial \mathrm{r}}-\frac{1}{\alpha} \frac{\partial \mathrm{T}}{\partial \mathrm{t}}+\frac{\mathrm{q}^{\cdot \cdot \prime \prime}}{\mathrm{K}}=0,
$$

where $\mathrm{T}, \mathrm{r}, \alpha, \mathrm{t}, \mathrm{q} \cdot{ }^{\prime \prime}$, and $\mathrm{K}$ are the temperature, radial distance, thermal diffusivity, time, heat generation rate, and thermal conductivity, respectively. The initial condition that corresponds to a steady-state solution for temperature in a cylinder with a constant heat source q.", is

$$
\begin{aligned}
\mathrm{T} & =\mathrm{T}_{0}+\left(\mathrm{T}_{\mathrm{si}}-\mathrm{T}_{0}\right)+\frac{\mathrm{q}^{\prime \prime \prime} \mathrm{R}^{2}}{4 \mathrm{~K}}\left(1-\mathrm{r}^{* 2}\right) \\
& =\mathrm{T}_{0}+\left(\mathrm{T}_{\mathrm{si}}-\mathrm{T}_{0}\right)+\Phi\left(1-\mathrm{r}^{* 2}\right)
\end{aligned}
$$




$$
=\mathrm{T}_{0}+\mathrm{dT}_{\mathrm{q}-\text { steady }} .
$$

Here, $\left(T_{s i}-T_{0}\right)$ is the rise in surface temperature due to the heat source, $T_{0}$ is the initial temperature in a package without a heat source, $R$ is the radius of the cylinder, $\mathrm{r}^{*}(=\mathrm{r} / \mathrm{R})$ is the dimensionless radial distance, $\mathrm{dT}_{\mathrm{q} \text {-steady }}$ is the temperature rise in a package due to the heat source, and

$$
\Phi=\frac{\mathrm{q}^{\cdot \cdot ' \mathrm{R}^{2}}}{4 \mathrm{~K}}=\frac{\mathrm{dT}_{\mathrm{q}-\text { steady }}-\left(\mathrm{T}_{\mathrm{si}}-\mathrm{T}_{0}\right)}{\left(1.0-\mathrm{r}^{*^{2}}\right)} .
$$

The boundary condition for a cylinder subjected to step surface temperatures $T_{S 1}$ for time $<t_{1}$, and $T_{s 2}$ for time $>t_{1}$ is

$$
\begin{aligned}
& T_{\mathrm{r}^{*}=1}=T_{\mathrm{S} 1} \text { for } 0<\mathrm{t} \leq \mathrm{t}_{1}, \text { and } \\
& \mathrm{T}_{\mathrm{r}^{*}=1}=\mathrm{T}_{\mathrm{S} 2} \text { for } \mathrm{t}>\mathrm{t}_{1} .
\end{aligned}
$$

Because Eq. 22 is a linear differential equation, the solution can be obtained by summing the solutions, $T=T_{1}+T_{2}+T_{3}$, of three separate problems of $\mathrm{T}_{1}, \mathrm{~T}_{2}$, and $\mathrm{T}_{3}$.

\subsection{PROBLEM 1}

Consider the case of a cylinder with a constant internal heat source, zero initial temperature, and zero surface temperature. The governing equation to be solved is

$$
\frac{\partial^{2} \mathrm{~T}_{1}}{\partial \mathrm{r}^{2}}+\frac{1}{\mathrm{r}} \frac{\partial \mathrm{T}_{1}}{\partial \mathrm{r}}-\frac{1}{\alpha} \frac{\partial \mathrm{T}_{1}}{\partial \mathrm{t}}+\frac{\mathrm{q}^{\prime \prime \prime}}{\mathrm{K}}=0 .
$$

The corresponding initial and boundary conditions are

$$
\mathrm{T}_{1}=\mathrm{O} \text { for } \mathrm{t}=\mathrm{O},
$$

and

$$
\mathrm{T}_{1}=0 \text { for } \mathrm{r}^{*}=1
$$


respectively. The solution of Eq. 26 for temperature $T_{1}$ with the initial and boundary conditions expressed by Eqs. 27 and 28, as given by Eq. 1 in Section 6.9 Carslaw and Jaeger, ${ }^{2}$ is

$$
T_{1}=\frac{q^{\cdot \cdot \prime} R^{2}}{4 K}\left[\left(1-r^{* 2}\right)-8 \sum_{n=1}^{\infty} \exp \left(\frac{-\beta_{n}^{2} \alpha \cdot t}{R^{2}}\right) \frac{J_{0}\left(r^{*} \beta_{n}\right)}{\beta_{n}^{3} J_{1}\left(\beta_{n}\right)}\right] .
$$

In Eq. 29, $J_{n}(\beta)$ is the Bessel function of the first kind of order $n$, and $\pm\left(\beta_{n}\right)$, $n=1,2, \ldots$, are the roots of the Bessel function $J_{0}(\beta)=0$. Equation 29 can be rewritten as

$$
T_{1}=\Phi\left(1-r^{* 2}\right)-8 \Phi \sum_{n=1}^{\infty} \frac{\Psi_{n}}{\beta_{n}^{2}}
$$

where

$$
\Phi=\frac{\mathrm{q}^{\cdot \cdot+\mathrm{R}^{2}}}{4 \mathrm{~K}}=\frac{\mathrm{dT}_{\mathrm{q}-\text { steady }}-\left(\mathrm{T}_{\mathrm{si}}-\mathrm{T}_{0}\right)}{\left(1.0-\mathrm{r} *^{2}\right)}
$$

and

$$
\psi_{n}=\exp \left(\frac{-\beta_{n}^{2} \alpha t}{R^{2}}\right) \frac{J_{0}\left(r^{*} \beta_{n}\right)}{\beta_{n} J_{1}\left(\beta_{n}\right)}
$$

\subsection{PROBLEM 2}

Consider the case of a cylinder with no internal heat source, a prescribed initial parabolic temperature distribution, and zero surface temperature.

The governing equation to be solved is

$$
\frac{\partial^{2} \mathrm{~T}_{2}}{\partial \mathrm{r}^{2}}+\frac{1}{\mathrm{r}} \frac{\partial \mathrm{T}_{2}}{\partial \mathrm{r}}-\frac{1}{\alpha} \frac{\partial \mathrm{T}_{2}}{\partial \mathrm{t}}=0
$$

The corresponding initial and boundary conditions are

$$
\mathrm{T}_{2}=\mathrm{T}_{\mathrm{si}}+\frac{\mathrm{q}^{\cdot \cdot ' \mathrm{R}^{2}}}{4 \mathrm{~K}}\left(1-\mathrm{r}^{* 2}\right) \text { for } \mathrm{t}=0
$$

and

$$
\mathrm{T}_{2}=0 \text { for } \mathrm{r}^{*}=1
$$


respectively. The solution of Eq. 33 with the initial and boundary conditions defined in Eqs. 34 and 35, as given by Eq. 7 in Section 6.6 of Carslaw and Jaeger, ${ }^{2}$ is

$$
T_{2}=2 \sum_{n=1}^{\infty} \exp \left(\frac{-\beta_{n}^{2} \alpha t}{R^{2}}\right) \frac{J_{0}\left(r^{*} \beta_{n}\right)}{\beta_{n}^{2} J_{1}^{2}\left(\beta_{n}\right)}\left[T_{s i} \beta_{n} J_{1}\left(\beta_{n}\right)+\frac{q^{\cdot ' \cdot} R^{2}}{2 K} J_{2}\left(\beta_{n}\right)\right] .
$$

Because, from Eq. 26 of Gray, Mathews, and Macrobert, ${ }^{3}$

$$
\frac{2 J_{1}\left(\beta_{n}\right)}{\beta_{n}}=J_{0}\left(\beta_{n}\right)+J_{2}\left(\beta_{n}\right)
$$

and, because $\pm\left(\beta_{n}\right)$ are the roots of the Bessel function $J_{0}\left(\beta_{n}\right)=0$,

$$
\mathrm{J}_{2}\left(\beta_{\mathrm{n}}\right)=\frac{2 \mathrm{~J}_{1}\left(\beta_{\mathrm{n}}\right)}{\beta_{\mathrm{n}}}
$$

Therefore, Eq. 36 simplifies to

$$
\begin{aligned}
T_{2} & =2 \sum_{n=1}^{\infty} \exp \left(\frac{-\beta_{n}^{2} \alpha t}{R^{2}}\right) \frac{J_{0}\left(r * \beta_{n}\right)}{\beta_{n}^{2} J_{1}^{2}\left(\beta_{n}\right)}\left[T_{s i} \beta_{n} J_{1}\left(\beta_{n}\right)+\frac{q^{\prime \prime \prime} R^{2}}{K} \frac{J_{1}\left(\beta_{n}\right)}{\beta_{n}}\right] \\
& =2 \sum_{n=1}^{\infty} \exp \left(\frac{-\beta_{n}^{2} \alpha t}{R^{2}}\right) \frac{J_{0}\left(r^{*} \beta_{n}\right)}{\beta_{n} J_{1}\left(\beta_{n}\right)}\left[T_{s i}+\frac{q^{\prime \prime \prime} R^{2}}{K} \frac{1}{\beta_{n}^{2}}\right] \\
& =\sum_{n=1}^{\infty} \psi_{n}\left[2 T_{s i}+\frac{8 \Phi}{\beta_{n}^{2}}\right] .
\end{aligned}
$$

\subsection{PROBLEM 3}

Consider the case of a cylinder with no internal heat source, zero initial temperature, and a step surface temperature boundary condition. The governing equation to be solved is

$$
\frac{\partial^{2} \mathrm{~T}_{3}}{\partial \mathrm{r}^{2}}+\frac{1}{\mathrm{r}} \frac{\partial \mathrm{T}_{3}}{\partial \mathrm{r}}-\frac{1}{\alpha} \frac{\partial \mathrm{T}_{3}}{\partial \mathrm{t}}=0 .
$$

The corresponding initial and boundary conditions are 


$$
\mathrm{T}_{3}=0 \text { for } \mathrm{t}=0 \text {, }
$$

and

$$
\begin{array}{ll}
\mathrm{T}_{3}=\mathrm{T}_{\mathrm{s} 1} & \text { for } 0<\mathrm{t} \leq \mathrm{t}_{1} \text { at } \mathrm{r}^{*}=1 \text { and } \\
\mathrm{T}_{3}=\mathrm{T}_{\mathrm{s} 2} & \text { for } \mathrm{t}>\mathrm{t}_{1} \text { at } \mathrm{r}^{*}=1,
\end{array}
$$

respectively. The solution of Eq. 40 for $\mathrm{T}_{3}$ with the initial and boundary conditions defined in Eqs. 41 and 42 , as given by Eq. 8 in Section 6.6 of Carslaw and Jaeger, ${ }^{2}$ is

$$
T_{3}=T_{s 1}-2 T_{s 1} \sum_{n=1}^{\infty} \exp \left(\frac{-\beta_{n}^{2} \alpha t}{R^{2}}\right) \frac{J_{0}\left(r^{*} \beta_{n}\right)}{\beta_{n} J_{1}\left(\beta_{n}\right)}
$$

for $\mathrm{t} \leq \mathrm{t}_{1}$ and

$$
\begin{aligned}
T_{3}= & T_{s 2}-2 T_{s 1} \sum_{n=1}^{\infty} \exp \left(\frac{-\beta_{n}^{2} \alpha t}{R^{2}}\right) \frac{J_{0}\left(r^{*} \beta_{n}\right)}{\beta_{n} J_{1}\left(\beta_{n}\right)} \\
& -2\left(T_{s 2}-T_{s 1}\right) \sum_{n=1}^{\infty} \exp \left(\frac{-\beta_{n}^{2} \alpha\left(t-t_{1}\right)}{R^{2}}\right) \frac{J_{0}\left(r^{*} \beta_{n}\right)}{\beta_{n} J_{1}\left(\beta_{n}\right)}
\end{aligned}
$$

for $t>t_{1}$. The solution can be rewritten as

$$
\mathrm{T}_{3}=\mathrm{T}_{\mathrm{s} 1}-2 \mathrm{~T}_{\mathrm{s} 1} \sum_{\mathrm{n}=1}^{\infty} \psi_{\mathrm{n}}
$$

for $\mathrm{t} \leq \mathrm{t}_{1}$ and

$$
T_{3}=T_{s 2}-2 T_{s 1} \sum_{n=1}^{\infty} \psi_{n}-2\left(T_{s 2}-T_{s 1}\right) \sum_{n=1}^{\infty} \psi_{n}^{\prime}
$$

for $t>t_{1}$. Here, $\psi_{n}^{\prime}$ is defined as

$$
\psi_{n}^{\prime}=\exp \left(\frac{-\beta_{n}^{2} \alpha\left(t-t_{1}\right)}{R^{2}}\right) \frac{J_{0}\left(r^{*} \beta_{n}\right)}{\beta_{n} J_{1}\left(\beta_{n}\right)} .
$$




\subsection{SOLUTION FOR TEMPERATURE T}

The final solution of Eq. 22 is

$$
\mathrm{T}=\mathrm{T}_{1}+\mathrm{T}_{2}+\mathrm{T}_{3},
$$

i.e.,

$$
\mathrm{T}=\Phi\left(1-\mathrm{r}^{* 2}\right)-8 \Phi \sum_{\mathrm{n}=1}^{\infty} \frac{\psi_{\mathrm{n}}}{\beta_{\mathrm{n}}^{2}}+\sum_{\mathrm{n}=1}^{\infty} \psi_{\mathrm{n}}\left(2 \mathrm{~T}_{\mathrm{si}}+\frac{8 \Phi}{\beta_{\mathrm{n}}^{2}}\right)+\mathrm{T}_{\mathrm{s} 1}-2 \mathrm{~T}_{\mathrm{s} 1} \sum_{\mathrm{n}=1}^{\infty} \psi_{\mathrm{n}}
$$

for $\mathrm{t} \leq \mathrm{t}_{1}$ and

$$
\begin{aligned}
T= & \Phi\left(1-r^{* 2}\right)-8 \Phi \sum_{n=1}^{\infty} \frac{\Psi_{n}}{\beta_{n}^{2}}+\sum_{n=1}^{\infty} \Psi_{n}\left(2 T_{s i}+\frac{8 \Phi}{\beta_{n}^{2}}\right) \\
& +T_{s 2}-2 T_{s 1} \sum_{n=1}^{\infty} \psi_{n}-2\left(T_{s 2}-T_{s 1}\right) \sum_{n=1}^{\infty} \psi_{n}^{\prime}
\end{aligned}
$$

for $t>t_{1}$. Eqs. 48 and 49 further simplify to

$$
\mathrm{T}=\mathrm{T}_{\mathrm{s} 1}+\Phi\left(1-\mathrm{r}^{* 2}\right)-2\left(\mathrm{~T}_{\mathrm{s} 1}-\mathrm{T}_{\mathrm{si}}\right) \sum_{\mathrm{n}=1}^{\infty} \psi_{\mathrm{n}}
$$

or

$$
\mathrm{T}=\mathrm{T}_{0}+\mathrm{dT}_{\mathrm{q}-\text { steady }}+\left(\mathrm{T}_{\mathrm{s} 1}-\mathrm{T}_{\mathrm{si}}\right)\left(1-2 \sum_{\mathrm{n}=1}^{\infty} \psi_{\mathrm{n}}\right),
$$

for $\mathrm{t} \leq \mathrm{t}_{1}$ and

$$
\mathrm{T}=\mathrm{T}_{\mathrm{s} 2}+\Phi\left(1-\mathrm{r}^{* 2}\right)-2\left(\mathrm{~T}_{\mathrm{s} 1}-\mathrm{T}_{\mathrm{si}}\right) \sum_{\mathrm{n}=1}^{\infty} \psi_{\mathrm{n}}-2\left(\mathrm{~T}_{\mathrm{s} 2}-\mathrm{T}_{\mathrm{s} 1}\right) \sum_{\mathrm{n}=1}^{\infty} \psi_{\mathrm{n}}^{\prime}
$$

or

$$
\mathrm{T}=\mathrm{T}_{0}+\mathrm{dT}_{\mathrm{q}-\text { steady }}+\left(\mathrm{T}_{\mathrm{s} 2}-\mathrm{T}_{\mathrm{si}}\right)-2\left(\mathrm{~T}_{\mathrm{s} 1}-\mathrm{T}_{\mathrm{si}}\right) \sum_{\mathrm{n}=1}^{\infty} \psi_{\mathrm{n}}-2\left(\mathrm{~T}_{\mathrm{s} 2}-\mathrm{T}_{\mathrm{s} 1}\right) \sum_{\mathrm{n}=1}^{\infty} \psi_{\mathrm{n}}^{\prime}
$$

for $t>t_{1}$. 


\subsection{EFFECT OF HEAT SOURCE}

The temperature rise in a cylinder due to an internal heat source can be determined by comparing the solutions of Eqs. 50-53 and 17 and 18, for the two cases, with and without heat source, respectively. Therefore,

$$
\mathrm{d} \mathbf{T}_{\mathrm{q}}=\mathrm{T}_{\mathrm{q} \neq 0}-\mathrm{T}_{\mathrm{q}=0}=\Phi\left(1-\mathrm{r}^{* 2}\right)+2\left(\mathrm{~T}_{\mathrm{si}}-\mathrm{T}_{0}\right) \sum_{\mathrm{n}=1}^{\infty} \psi_{\mathrm{n}}
$$

or

$$
\mathrm{T}_{\mathrm{q} \neq 0}-\mathrm{T}_{\mathrm{q}=0}=\mathrm{dT} \mathrm{T}_{\mathrm{q}-\text { steady }}-\left(\mathrm{T}_{\mathrm{si}}-\mathrm{T}_{0}\right)\left(1-2 \sum_{\mathrm{n}=1}^{\infty} \psi_{\mathrm{n}}\right)
$$

\subsection{HYPOTHETICAL-ACCIDENT CONDITIONS}

\subsubsection{Case when $T_{s i} \neq 100^{\circ} \mathrm{F}$}

The solution of Eq. 22 for the hypothetical-accident surface temperature boundary conditions:

$$
\mathrm{T}_{0}=100^{\circ} \mathrm{F}, \mathrm{T}_{\mathrm{s} 1}=1475^{\circ} \mathrm{F}, \quad \mathrm{T}_{\mathrm{s} 2}=100^{\circ} \mathrm{F} \text {, and } \mathrm{t}_{1}=1800 \mathrm{~s}(30 \mathrm{~min}),
$$

as shown in Fig. 3 , is

$$
\mathrm{T}=100+\mathrm{dT}_{\mathrm{q}-\text { steady }}+\left(1475-\mathrm{T}_{\mathrm{si}}\right)\left(1-2 \sum_{\mathrm{n}=1}^{\infty} \psi_{\mathrm{n}}\right)
$$

for $\mathrm{t} \leq 1800 \mathrm{~s}(30 \mathrm{~min})$ and

$$
\mathrm{T}=100+\mathrm{dT}_{\mathrm{q}-\text { steady }}-\left(\mathrm{T}_{\mathrm{si}}-100\right)-2\left(1475-\mathrm{T}_{\mathrm{si}}\right) \sum_{\mathrm{n}=1}^{\infty} \Psi_{\mathrm{n}}+2(1375) \sum_{\mathrm{n}=1}^{\infty} \Psi_{\mathrm{n}}^{\prime}
$$

for $\mathrm{t}>1800 \mathrm{~s}$ (30 min). The effect of a heat source, obtained by comparing the solutions of Eqs. 56 and 57 and 19 and 20, is

$$
\mathrm{T}_{\mathrm{q} \neq 0}-\mathrm{T}_{\mathrm{q}=0}=\mathrm{dT}_{\mathrm{q}-\text { steady }}-\left(\mathrm{T}_{\mathrm{si}}-100\right)\left(1-2 \sum_{\mathrm{n}=1}^{\infty} \psi_{\mathrm{n}}\right) .
$$

\subsubsection{Case when $T_{s i}=100^{\circ} \mathrm{F}$}

For a cylinder with no internal heat source, the initial surface temperature $\mathrm{T}_{\mathrm{si}}$ is equal to the initial ambient temperature $\mathrm{T}_{0}\left(=100^{\circ} \mathrm{F}\right)$. Equations 56-58 simplify to

$$
\mathrm{T}=100+1375\left(1-2 \sum_{\mathrm{n}=1}^{\infty} \psi_{\mathrm{n}}\right)+\mathrm{d} \mathrm{T}_{\mathrm{q}-\text { steady }}
$$


for $\mathrm{t} \leq 1800 \mathrm{~s}$ and

$$
\mathrm{T}=100+2(1375)\left(\sum_{\mathrm{n}=1}^{\infty} \psi_{\mathrm{n}}^{\prime}-\sum_{\mathrm{n}=1}^{\infty} \psi_{\mathrm{n}}\right)+\mathrm{dT}_{\mathrm{q}-\text { steady }}
$$

for $t>1800 \mathrm{~s}$. Comparison of Eqs. 59 and 60 with the solutions to Eqs. 19 and 20 , obtained for the case of no internal heat source, show that

$$
\mathrm{T}_{\mathrm{q} \neq 0}-\mathrm{T}_{\mathrm{q}=0}=\mathrm{dT}_{\mathrm{q} \text {-steady }}
$$

when $\mathrm{T}_{\mathrm{si}}=100^{\circ} \mathrm{F}$.

\subsection{MAXIMUM TEMPERATURE}

The maximum temperature in a cylinder will occur when

$$
\partial \mathrm{T} / \partial \mathrm{t}=0
$$

or

$$
2(1375) \sum_{n=1}^{\infty} \psi_{n}^{\prime} \frac{\beta_{n}^{2} \alpha}{R^{2}}=2\left(1475-T_{s i}\right) \sum_{n=1}^{\infty} \psi_{n} \frac{\beta_{n}^{2} \alpha}{R^{2}}
$$

This equation can be solved iteratively for various values of $T_{\mathrm{si}}, \mathrm{r}^{*}$, and $\mathrm{R}^{2} / \alpha$ to compute time $\mathrm{t}_{\mathrm{Tmax}}$ when the temperature will be maximum. Time $\mathrm{t}_{\text {Tmax }}$ can then be substituted in the solution to obtain the maximum temperature.

No attempt has been made to solve Eq. 62 because the estimating procedure presented in this paper does not require the solution of Eq. 62, and the use of Eq. 62, with three independant parameters, will make the estimating procedure more difficult.

\section{CONSERVATIVE PROCEDURE}

A procedure is considered conservative when the procedureestimated maximum temperature is greater than or equal to the maximum temperature that a package will experience during a hypothetical-accident thermal-test condition, i.e.,

$$
\mathrm{T}_{\text {max-estimation }} \geq \mathrm{T}_{\text {max-package }} \text {. }
$$

The present procedure can, therefore, be considered conservative if 


$$
\mathrm{T}_{\text {max-estimation }}=\mathrm{T}_{\max \text {-analytic }, \mathrm{q}=0}+\mathrm{dT}_{\mathrm{q} \text {-steady }} \geq \mathrm{T}_{\text {max-package }} \text {. }
$$

The following sections explain why the proposed procedure is expected to provide conservative estimates.

\subsection{NO INTERNAL HEAT SOURCE}

For the case of a package with no heat source, the term $\mathrm{dT}_{\mathrm{q} \text {-steady }}$ is zero; thus, the procedure is conservative if

$$
\mathrm{T}_{\text {max-estimation }, \mathrm{q}=0}=\mathrm{T}_{\text {max }} \text {-analytic, } \mathrm{q}=0 \geq \mathrm{T}_{\text {max }} \text {-package }, \mathrm{q}=0 .
$$

The example presented in Section 5 has already shown that the

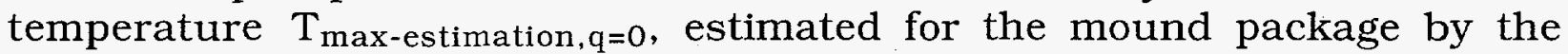
proposed procedure, is higher than $\mathrm{T}_{\text {max-package, } \mathrm{q}=0 \text {, the temperature }}$ obtained from a detailed numerical model of the package and the HEATING6 computer code. The following discussion will further explain why the maximum temperature in the analytical model $T_{\text {max-analytic, } q=0}$ will be higher than $T_{\text {max-package, } q=0}$, the maximum temperature that a package will experience under hypothetical-accident thermal-test conditions.

1. The surface temperature conditions that a package will experience under a hypothetical-accident thermal test, specified in 10 CFR \$71.73 of the Code of Federal Regulations and imposed in the analytical model, are presented in Fig. 12. This figure shows that the heat inflow rate during the first $30 \mathrm{~min}$ and the total heat flow into a package will be higher in the analytical model than in a package under the conditions specified in 10 CFR $\$ 71.73$. Therefore,

$$
T_{\text {analytic, } q=0} \geq T_{\text {package }, q=0} \text { for } t \leq 30 \mathrm{~min} \text {. }
$$

Fig. 12. Surface temperature conditions experienced by package under hypothetical-accident thermal test specified in 10 CFR $\$ 71.73$ and imposed in the analytical model

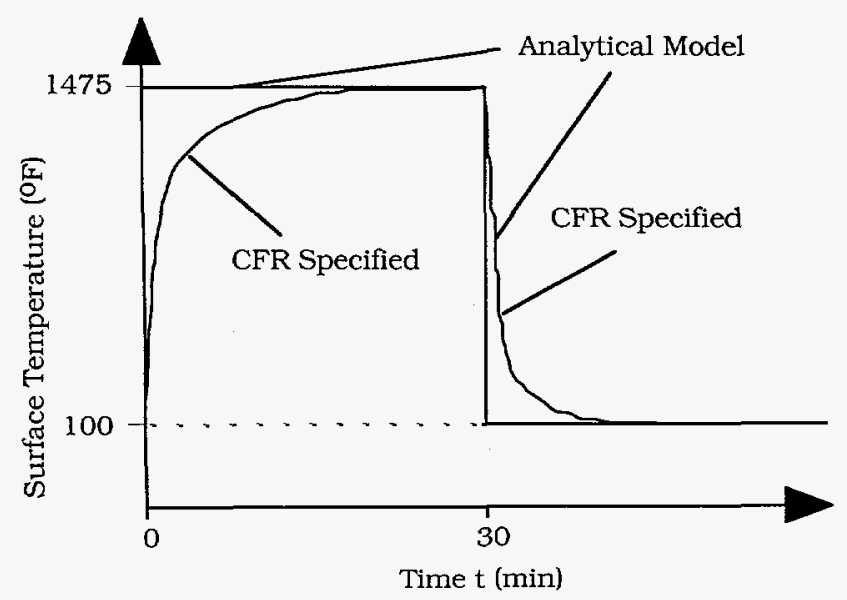


For time $>30 \mathrm{~min}$, some of the heat that penetrated during the first 30 min will continue to flow inward to raise the temperature of the inner region, even though the heat flow at the surface is now in the outward direction. Because

$$
\text { QTotal-Inflow,analytic } \geq T_{\text {Total-Inflow,package }}
$$

and the heat inflow in the internal region continues until all regions of a package have attained their maximum temperature, the estimated temperature of the inner region will generally be higher, even though the heat outflow rate at the surface for time $>30 \mathrm{~min}$ is higher in the case of the analytical model.

2. To provide thermal protection during a hypothetical-accident fire event, the outer section (overpack) of a transportaion package is generally packed with an insulating material. The thermal diffusivity of the inner region of a package is, therefore, generally higher than that of the outer region. The analytical model, in contrast, assumes one uniform thermal diffusivity for the entire region of a package.

To illustrate the effect of thermal diffusivity on temperature, onedimensional, steady-state temperature distributions in two solids are shown in Fig. 13. The solid with a uniform thermal diffusivity represents the analytical model. The solid with two thermal diffusivities, with the higher value in the inner region, represents a package. It can be seen from this figure that the temperature in a solid with a higher thermal-diffusivity material in the inner region will be lower than that in a solid with a uniform thermal diffusivity. The reason for this lower temperature is that the higher conducting inner region allows the heat to penetrate deeper and faster and thus lowers the temperature. Although, the figure shows a steady-state case, the temperature behavior will be similar even if the heat flow conditions are transient.

For a package with no internal heat source, it can be concluded that

$$
\mathrm{T}_{\text {max-analytic, } \mathrm{q}=0} \geq \mathrm{T}_{\text {max-package, } \mathrm{q}=0} \text {. }
$$

\subsection{INTERNAL HEAT SOURCE $\mathbf{Q} \neq 0$}

For the case of a package with an internal heat source, the procedure is conservative if 


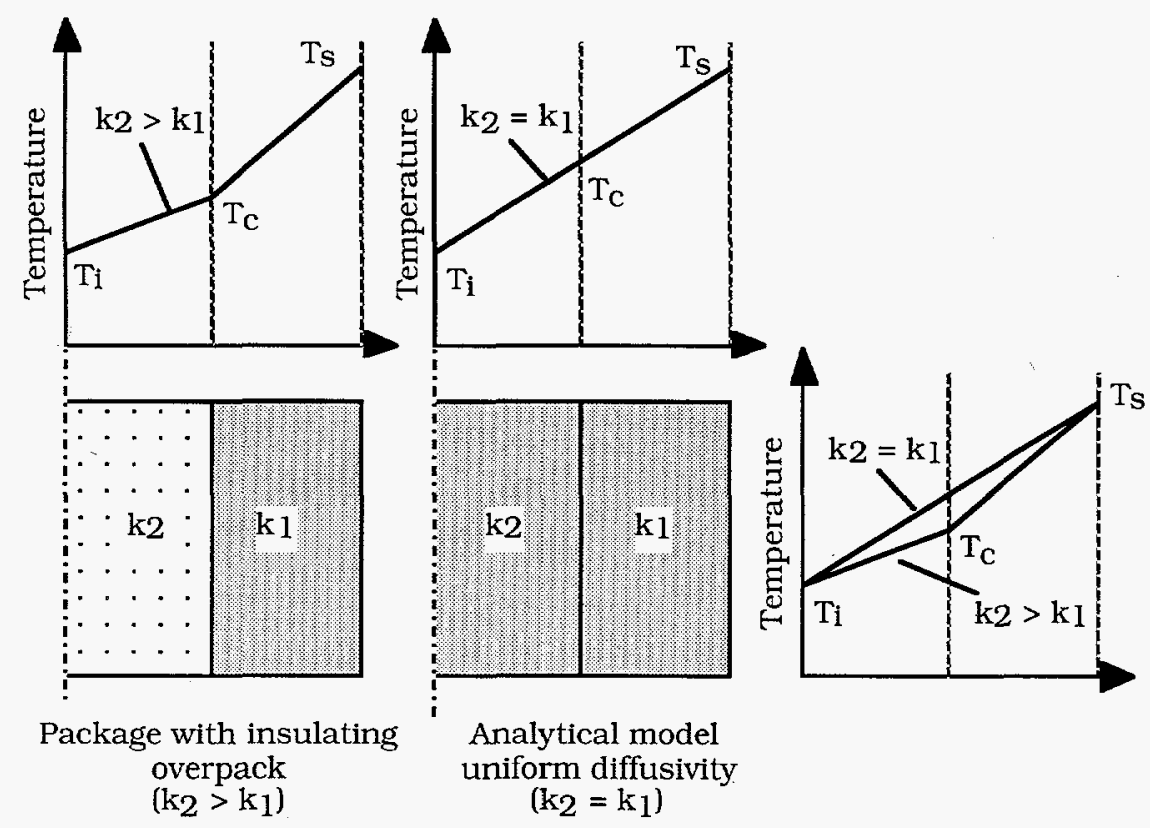

Fig. 13. Steady-state temperature distributions in two solids, one with uniform diffusivity, the other with two diffusivities

$T_{\text {max-estimation, } q \neq 0} \geq T_{\max \text {-package, } q \neq 0}$,

i.e.,

$\mathrm{T}_{\max \text {-analytic, } \mathrm{q}=0}+\mathrm{d} \mathrm{T}_{\mathrm{q} \text {-steady }} \geq \mathrm{T}_{\max \text {-package, } \mathrm{q}=0}+\mathrm{d} \mathrm{T}_{\max \text {-package, } \mathrm{q} \neq 0 .}$

Here,

$$
\mathrm{dT}_{\text {max }} \text { package, } \mathrm{q} \neq 0
$$

is the maximum temperature rise in a package due to an internal heat source. Because

$$
\mathrm{T}_{\max \text {-analytic, } \mathrm{q}=0} \geq \mathrm{T}_{\max } \text {-package, } \mathrm{q}=0,
$$

from Eq. 66 , the procedure is conservative if

$$
\mathrm{dT}_{\mathrm{q} \text {-steady }} \geq \mathrm{dT} \mathrm{T}_{\text {max-package, } q \neq 0} \text {. }
$$

The following discussion shows why the term $\mathrm{dT}_{\mathrm{q} \text {-steady }}$ will be greater than or equal to $\mathrm{dT}_{\text {max }}$-package, $q \neq 0$. 
1. Suppose the ambient temperature for two identical packages, one with a constant internal heat source and the other with no heat source, is raised from $\mathrm{T}_{0}$ (assume $100^{\circ} \mathrm{F}$ ) to $\mathrm{T}_{\mathrm{sl}}$ (assume $1475^{\circ} \mathrm{F}$ ) and then kept constant at $\mathrm{T}_{\mathrm{s} 1}$ for an infinite time period. The final asymptotic maximum temperature in these packages, as shown in Fig. 14, will be

$$
\begin{aligned}
\mathrm{T}_{\text {max-package, } \mathrm{q} \neq 0, \text { asymptotic }} & =\mathrm{T}_{\mathrm{sl}}+\left(\mathrm{T}_{\text {package-steady }}-\mathrm{T}_{0}\right) \\
& =\mathrm{T}_{\mathrm{s} 1}+\mathrm{dT}_{\mathrm{q}, \text { steady }},
\end{aligned}
$$

and

$T_{\text {max-package, } q=0, \text { asymptotic }}=T_{\mathrm{S} 1}$,

respectively. Therefore,

$$
\left(T_{\text {max }, \text { package }, q \neq 0}-T_{\text {max }, \text { package }, q=0}\right)_{\text {asymptotic }}=d T_{q, \text { steady }}
$$

or

$$
\left(\mathrm{dT}_{\text {max-package }, q \neq 0}\right)_{\text {asymptotic }}=\mathrm{dT}_{\mathrm{q}, \text { steady }}
$$

or

$$
\mathrm{dT}_{\text {max }} \text {-package, } q \neq 0 \leq \mathrm{dT}_{\mathrm{q}, \text { steady }} .
$$

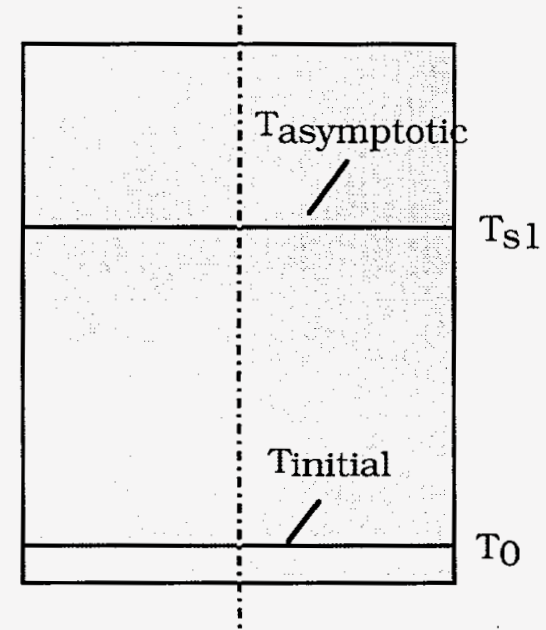

Package $(\mathrm{q}=0)$

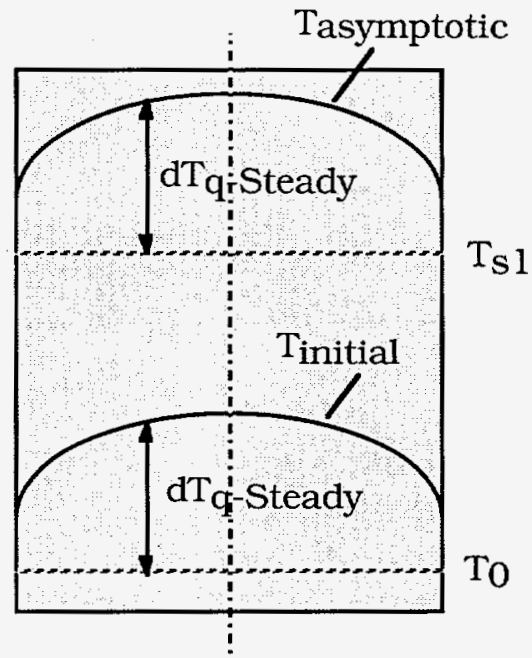

Package $(q \neq 0)$

Fig. 14. Asymptotic temperature distribution in two packages, one with, the other without an internal heat source, as ambient temperature is raised from $T_{O}$ to $T_{S 1}$ and held at $T_{S 1}$ for infinite time 
2. The comparison of the analytical solutions for temperature in two infinite cylinders subjected to step surface temperature boundary conditions, one with an internal heat source (Section 6) and one without heat source (Section 7), shows that

$$
\mathrm{T}_{\mathrm{cyl}, \mathrm{q} \neq 0}-\mathrm{T}_{\mathrm{cyl}, \mathrm{q}=0}=\mathrm{d} \mathrm{T}_{\mathrm{q}-\text { steady }}-\left(\mathrm{T}_{\mathrm{si}}-\mathrm{T}_{0}\right)\left(1-2 \sum_{\mathrm{n}=1}^{\infty} \psi_{\mathrm{n}}\right)
$$

Because the argument $\left(\beta_{n}^{2} \alpha t / R^{2}\right)$ is always positive, the value of the exponential function $\exp \left(-\beta_{n}^{2} \alpha t / R^{2}\right)$ ranges between zero and one. Therefore, the maximum value of the term $\psi_{\mathrm{n}}$ is

$$
\left(\psi_{n}\right)_{\max }=\left(\exp \left(\frac{-\beta_{n}^{2} \alpha t}{R^{2}}\right) \frac{J_{0}\left(r^{*} \beta_{n}\right)}{\beta_{n} J_{1}\left(\beta_{n}\right)}\right)_{\max }=\frac{J_{0}\left(r^{*} \beta_{n}\right)}{\beta_{n} J_{1}\left(\beta_{n}\right)} .
$$

The term $\left(\mathrm{T}_{\mathrm{si}}-\mathrm{T}_{0}\right)$ is positive because the initial steady-state surface temperature $T_{s i}$ in a package with an internal heat source will always be greater than the initial ambient temperature $T_{0}$. Also, from the properties of the Bessel functions,

$$
\sum_{n=1}^{\alpha} \frac{J_{0}\left(r^{*} \beta_{n}\right)}{\beta_{n} J_{1}\left(\beta_{n}\right)}=0.5
$$

Therefore,

$$
0 \leq\left(1-2 \sum_{n=1}^{\infty} \Psi_{n}\right) \leq 1
$$

and

$$
0 \leq\left(\mathrm{T}_{\mathrm{si}}-\mathrm{T}_{0}\right)\left(1-2 \sum_{\mathrm{n}=1}^{\infty} \psi_{\mathrm{n}}\right) \leq\left(\mathrm{T}_{\mathrm{si}}-\mathrm{T}_{0}\right) .
$$

It can be seen from Eqs. 77 and 81 that

$$
\mathrm{T}_{\text {cyl }, \mathrm{q} \neq 0}-\mathrm{T}_{\text {cyl, } \mathrm{q}=0} \leq \mathrm{dT} \mathrm{T}_{\mathrm{q}, \mathrm{steady}}
$$

or

$$
\mathrm{dT}_{\mathrm{cyl}, \mathrm{q} \neq 0} \leq \mathrm{dT}_{\mathrm{q}, \text { steady }}
$$

or 


$$
\mathrm{dT}_{\max , \mathrm{cyl}, \mathrm{q} \neq 0} \leq \mathrm{dT}_{\mathrm{q}, \text { steady }} .
$$

Inasmuch as the hypothetical-accident thermal test condition is less severe than the step surface temperature condition imposed in the analytical solution for temperature in an infinite circular cylinder, the concluding Eq. 84, valid for a cylinder, can also be considered valid for a package undergoing a hypothetical-accident thermal test, i.e.,

$$
\mathrm{dT}_{\mathrm{q} \text {-steady }} \geq \mathrm{dT}_{\text {max-package, }} \neq \neq 0 .
$$

Therefore, for a package with an internal heat source, it can be concluded that

$$
\mathrm{T}_{\text {max-estimation, } \mathbf{q} \neq 0} \geq \mathrm{T}_{\text {max-package, } \mathbf{q} \neq 0} \text {. }
$$

\section{CONCLUSIONS}

We have presented a simple, easy-to-use estimating procedure that provides a conservative prediction of the maximum temperature of an inner container under conditions of a hypothetical-accident thermal event. The procedure is applicable to all packages, with or without an internal heat source, that are protected by rectangular or cylindrical thermal insulating overpacks. Designers and reviewers of transportation packages will find it beneficial to use this estimating procedure before commencing a very lengthy and detailed computer simulation.

\section{REFERENCES}

1. Code of Federal Regulations, $10 \mathrm{CFR} 71$, "Packaging and Transportation of Radioactive Materials," Office of the Federal Register, January 1, 1995.

2. Carslow, H. S. and Jaeger J. C., Conduction of Heat in Solids, 2nd Ed., Oxford University Press, London, 1959.

3. Gray, A. and Mathews, G. B., A Treatise on Bessel Functions and Their Applications to Physics, 2nd Ed., Macmillan Publishing Co., London, 1922 (1952 printing). 
Distribution for ANL -96/12

Internal

R. D. Carlson

R. B. Poeppel

R. A. Valentin

J. L. Fisher

V. L. Shah (20)

R. W. Weeks

C. A. Malefyt

C. E. Till

TIS Files

External

DOE-OSTI (2)

ANL Libraries

ANL-E

ANL-W

DOE-Chicago Field Office:

Manager

D. T. Goldman

F. Herbaty

A. L. Taboas

Energy Technology Division Review Committee:

H. K. Birnbaum, University of Illinois, Urbana

R. C. Buchanan, University of Cincinnati, Cincinnati, $\mathrm{OH}$

S.-N. Liu, Fremont, CA

H. S. Rosenbaum, Fremont, CA

R. K. Shah, University of Kentucky, Lexington

S. Smialowska, Ohio State University, Columbus

R. E. Smith, Altran Corp., Huntersville, NC

J. C. Anderson, ORNL, Oak Ridge, TN

$\mathrm{K}$. Battige, NRC, Washington, DC

R. W. Carlson, LLNL, Livermore, CA

R. Cooperstein, DOE, Washington, DC

A. Duffell, Roy S. Weston Co., Washington, DC

M. R. Feldman, ORNL, Oak Ridge, TN

G. F. Hohnstreiter, SNL, Albuquerque, NM

J. Hovingh, LLNL, Livermore, CA

A. Kapoor, DOE, Washington, DC

J. Koski, SNL, Albuquerque, NM

M. Krzaniak, Nordion International, Inc., Ontario Canada

W. Lake, DOE, Washington, DC

K. Nakajima, Mitsubishi Research Inst., Inc., Tokyo, Japan

S. Primeau, Eagle Research, Inc., Germantown, MD

T. Tomaszewski, Westinghouse Hanford Co., Richland, WA

R. Towell, Eagle Research, Inc., Germantown, MD

M. Wangler, DOE, Washington, DC 